\title{
Failure Prediction of Open-pit Mine Landslide Containing Complex Geological Structure using Inverse Velocity Method: A Case Study in West Open-Pit mine, Pingzhuang, China
}

Han Du

Tsinghua University

Danqing Song ( $\sim$ songdq2019@mail.tsinghua.edu.cn )

Tsinghua University

\section{Research Article}

Keywords: Failure time of landslide, Open-pit coal mine, Inverse velocity, Early warning, Field monitoring

Posted Date: June 24th, 2021

DOl: https://doi.org/10.21203/rs.3.rs-573230/v1

License: (a) (1) This work is licensed under a Creative Commons Attribution 4.0 International License.

Read Full License 
1 Failure prediction of open-pit mine landslide containing complex geological structure using inverse velocity method: A case study in West Open-Pit mine, Pingzhuang, China Han Du, Danqing Song* Department of Hydraulic Engineering, State Key Laboratory of Hydroscience and Engineering, Tsinghua University, Beijing, 100084, China *Corresponding author at: Department of Hydraulic Engineering, State Key Laboratory of Hydroscience and Engineering, Tsinghua University, Beijing 100084, China. Tel.:/Fax. +86-1062794910. E-mail address: danqingsonglzu@163.com (DQ. Song).

\section{Abstract}

In the field of open-pit geological risk management, landslide failure time prediction is one of the important topics. Based on the analysis of displacement monitoring data, the inverse velocity method (IVM) has become an effective method to solve this issue. In order to improve the reliability of landslide prediction, four filters were used to test the velocity time series, and the effect of landslide failure time prediction was compared and analyzed. The IVM is used to predict the failure time of open-pit coal mine landslide. The results show that the sliding process of landslide can be divided into three stages based on the IVM: the initial attenuation stage (regressive stage), the second attenuation stage (progressive stage), the linear reduction stage (autoregressive stage). The accuracy of the IVM is closely related to the measured noise of the monitoring equipment and the natural noise of the environment, which will affect the identification of different deformation stages. Compared with the raw data and the exponential smoothing filter (ESF) models, the fitting effect of short-term smoothing filter (SSF) and long-term smoothing filter (LSF) in the linear autoregressive stage is better. A slope displacement pixel difference 
method based on fitting accuracy and field monitoring signals is proposed to determine the point onsetof-acceleration (OOA) that is very important role for landslide prediction. A stratified prediction method combining SSF and LSF is proposed. The prediction method is divided into two levels, and the application of this method is given.

Keywords: Failure time of landslide; Open-pit coal mine; Inverse velocity; Early warning; Field monitoring

\section{Introduction}

Landslides are one of the most common natural disasters and have a significant impact on people's activities (Wu et al., 2018; Haque, 2019). Landslide stability is affected by many factors, such as rainfall (Gao et al. 2017; Chen et al. 2020), earthquake (Fan et al. 2016; Song et al. 2020a,b), geological structure, such as folds, discontinuities and faults (Kim et al. 2015); blasting (Liu et al. 2020), physical and chemical weathering (Admassu et al. 2012; Chen and Song 2021), and excavation (Song et al. 2020a,b). Rock mass movement and surface deformation are related phenomena caused by surface subsidence or landslide in open-pit mines (Tarolli and Sofia 2016; López-Vinielles et al., 2020) (as shown in Fig1). With the development of large-scale deep pit open-pit mining engineering activities, mine landslide disasters continue to occur all over the world, posing a serious threat to open-pit mining and human social safety (Ma et al. 2018; Liu et al., 2020). Under the condition that the production speed is fast and the safety of workers and equipments must be guaranteed at the same time, the correct and reasonable prediction of open-pit mine landslide can not only provide guidance for slope design and construction, but also reduce the social and economic harm caused by engineering accidents. Landslide failure has always been one of the most common geological disasters in open-pit mines, and landslide prediction 
has always been an important topic in the field of geotechnical engineering (Zare Naghadehi et al. 2013; Ma et al., 2018; Song et al., 2020c,d).

In recent years, many scholars have carried out a series of studies on the prediction time of landslide failure (Fukuzono 1985; Voight 1989; Ventura et al., 2009). In the laboratory geomechanical model tests and field tests, some methods can be used to predict the failure time of landslides (Bozzano et al. 2014; Chen and Jiang 2020). Although the prediction methods for the general rule of failure mechanism and time of all types of landslides do not yet exist, many achievements have been made in the previous research work, and a large number of empirical derivation methods and related equations have been obtained (Rose and Hungr 2007; Carlà et al. 2017). However, most analysis methods are regression analysis based on displacement or strain time series before landslide failure, and finally obtain the relationship related to some inherent properties of rock mass (Ventura et al., 2009). At present, the IVM based on creep theory is one of the most widely used methods in the prediction of landslide failure time (Dick et al. 2015). Fukuzono (1985) proposed the reverse velocity method, which provides a useful tool for interpreting monitoring data and can better predict the final slope failure time. Rose and Hungr (2007) used the IVM to predict the potential failure of rock slope in open-pit mines. Mufundirwa et al. (2010) adopted IVM (IVM) to predict the failure time of rock mass and landslide. Based on this, SLO method were proposed to predict the failure time of rock mass in Asamushi and Vaiont landslides. Osasan and Stacey (2014) investigated the failure of mine slope and establish a landslide warning model by using IVM. Carlà et al. (2017) predicted the time of different types of landslides using IVM, compared and analyzed the applicability of the four IVM models, and deduced the general criteria for convenient data smoothing processing. Zhou et al. (2020) introduced a controllable variable and proposed an improved IVM, which can reduce the prediction error caused by the decrease of acceleration before failure. 
Previous studies have shown that linear fitting of displacement time series by IVM is a simple and effective tool for predicting landslide failure time. However, the process of inferring appropriate linear trend lines and reliable fault predictions from inverse velocity diagrams is adversely affected by the noise in the measurement. In addition, due to the complex geological structure of open-pit landslides, IVM has certain limitations. For example, local slope movement, measurement error, human activities, rainfall etc will have an impact on the displacement rate, which will seriously affect the reliability and accuracy of the prediction results. Therefore, the application of IVM in time prediction of open-pit mines landslides needs to be further discussed, and some analysis strategies and applicability in INM need to be studied. In the field of landslide research, in-situ monitoring is a very important work to study the instability characteristics and failure mechanism of landslide (Liu et al. 2020; Du et al. 2020). Interpretation of monitoring data is one of the key points in predicting the timing of geomechanical failure or in assessing the probability of imminent collapse of a rock slope (He et al. 2018). The instruments available for slope monitoring in open-pit mines include precise measuring stations and prisms, inclinometers, global positioning system (GPS) equipment and seismometers (Dick et al., 2015; Ma et al. 2018; Liu et al. 2020;). The methods of surface and subsurface monitoring, data collection and evaluation are comprehensively described. A common method of interpreting the monitoring data is to convert the measured values into rates (velosities), in general, slope failure is preceded by increased rates of displacement, strain or microseismic activity, where displacement rates (velosities) are generally considered to be the best indicator of the failure process (Severin et al. 2014). In recent years, many efficient monitoring techniques have emerged. Ground-based radar is one of the most effective and powerful monitoring technologies, which is very suitable for landslide monitoring requirements (Luzi, 2010; Mazzanti, 2011). Radar slope monitoring is widely used worldwide, such as slope stabilization 
radar (SSR) and moving and surveying radar (MSR), which are currently used in many mines around the world. In recent years, ground-based radar has been widely used in landslide monitoring, and groundbased radar has made some achievements in landslide prediction (Bozzano et al., 2010; Dick et al., 2015; Tommaso et al., 2017). However, in order to fully realize the effectiveness of radar in the prediction of landslide failure in open-pit mines, it is necessary to establish a method that can efficiently predict the slope failure time by combining radar displacement monitoring.

In this work, taking an open-pit mine coal landslide as an example, the Ground-based Synthetic Aperture Radar monitoring system is used to monitor the displacement of the landslide, and the relevant displacement data before and during the landslide are obtained. The inverse velocity method is used to predict the sliding time of the landslide, which verifies the effectiveness of IVM in the prediction of the landslide time of the open pit mine, and provides an important basis for the prevention and control of the landslide and the mining of the open pit mine. The interference effects of engineering noise on IVM landslide time prediction, including strong noise and weak noise, were discussed in detailed. Four kinds of filters (Raw data, SSF, LSF, and ESF) are used to test the velocity time series, and the effect of landslide failure time prediction is compared and analyzed. A slope shift pixel difference method based on fitting accuracy and field monitoring signals is proposed to determine point OOA. A stratified prediction method combining SSF and LSF is proposed, and its applicability is analyzed.

\section{Study area}

The topographic of Pingzhuang Town is subordinated to intramontane basin, which is located on the north-eastward subhill ramp of Haer-nao Mountain. The perimeter of Pingzhuang Town contains the largest lignite reserves in Eastern of Inner Mongolia Autonomous Region with an apparent reserve of 
around 200 billion tonnes. With the increasing scale of open-pit mining, under the influence of a series of factors such as open pit, underground joint excavation, fault and weak layer, the landslide disaster is particularly prominent, which seriously threatens the safety production of open pit mine. There were more than 40 landslides of different sizes at the top of the mining area, with a total volume of 4 million cubic meters, which caused a series of safety production and geological environment problems in the open-pit mine.

A massive landslide occurred on the afternoon of 17 April 2013 in West Pit, an open-cast coal mine located approximately $6.73 \mathrm{~km}$ southwestern fringe of Yuanbao town, southeastern Inner Mongolia, China (Fig. 2). Satellite remote sensing image of Pingzhuang West Open-pit Mine were shown in Fig. 3. The front view and planar map of the landslide are shown in Fig. 4. Fig. 4 shows that after the occurrence of the landslide, the sliding body accumulates in the upper part of the coal seam, resulting in coal pressing phenomenon, which results in the failure of local coal seam mining. The landslide affected northern top slope of the open pit, resulting in the suspend production. Pingzhuang coalfield is situated composite zone between the Yinshan Mountains - Tianshan Mountains latitudinal structural belt and the northeastern neocathaysian system of second subsidence belt, the northern foothill of the Yanshan mountains of China. The region comprises a $405 \mathrm{~m}$ extra-thick siliciclastic sequence consists of quartz arenite and shale, which makes up the JIUFOTANG Fm Group of Jurassic system. The transition to the mantling volcanic sedimentation, which symbolizes the predominant lithosphere of YUANBAO SHAN FUXIN Group, was determined by several distinct and extremely fluctuating categories of alteration of underneath sandstone layers, central carboniferous, and overlying sandy-stone interval.

\section{Methodology}


3.1 Mathematical model of VMI landslide time prediction

The feedback dynamic result of the characteristic signal of an event in the past period is used to predict the characteristic information of the event in the future period of time, and the method with predictive ability input indexed by time is abstracted, which can be understood as a time series model. Saito proposed an improved method for landslide time prediction based on the traditional creep theory, by which the creep process was divided into three stages: average deformation, constant deformation and accelerated deformation (Fig. 5). To make the displacement time series data more stable, Fukuzono (1985) made improvement on this basis, and obtained that the logarithm of velocity and the logarithm of acceleration were proportional. Under the constant loading condition of the slope, the time under the corresponding time stamp of the landslide displacement can be expressed as follows:

$$
\frac{d^{2} x}{d t^{2}}=a\left(\frac{d x}{d t}\right)^{\alpha}
$$

where, the $x$ is the displacement time series, (unit: $\mathrm{m} / \mathrm{s}$ ); $T$ is the monitoring time (unit: $\mathrm{s}$ ); $a$ and $\alpha$ are

dimensionless constant parameters.

By comparing and analyzing the experimental results, Fukuzono (1985) determined that the value range of the dimensionless parameter was between 1.5 and 2.2. The correlation between displacement rate and landslide time can be expressed as follows:

$$
\frac{1}{v}=[a \cdot(\alpha-1)]^{\frac{1}{\alpha-1}}\left(t_{f}-t\right)^{\alpha \frac{1}{\alpha-1}}
$$

where, $v$ is the displacement change rate sequence, $\mathrm{m} / \mathrm{s} ; t_{f}$ is the predicted landslide time; $t$ is the time course of landslide evolution.

In addition, some scholars pointed out that both $\alpha$ and A can change with the change of time stampling, and the different values range of $\alpha$ is directly related to the morphological change of the curve (as shown 
in Fig. 6). When $\alpha>2$, the curve shows a protruding shape. When $\alpha \square(1,2)$, the curve is concave; When $\alpha=2$, the curve is linear. When $\alpha=2$, the landslide time can be calculated by the following formula:

$$
t_{f}=\left[t_{2} \cdot\left(\frac{1}{v}\right)_{1}-t_{1}\left(\frac{1}{v}\right)_{2}\right] /\left[\left(\frac{1}{v}\right)_{1}-\left(\frac{1}{v}\right)_{2}\right]
$$

The above relation is expressed as a more universal relation that can better describe the failure rate of the slope, as follows:

$$
\S=A \& q^{\alpha}
$$

Where, $\&$ and $\&$ are displacement acceleration and acceleration respectively.

By substituting Equation (2) and (3) into Equation 4, we can get:

$$
t_{f}-t=\left[\frac{\Omega^{(1-\alpha)}-\S_{f}^{(1-\alpha)}}{A(\alpha-1)}\right]
$$

If the prediction of landslide time is taken into account, the expression mode of inverse multiplication element of velocity data at slope sliding is regarded as infinite in Eq. (5), and the linear model can be used as a reference for landslide time prediction when the intercept of $\mathrm{X}$-axis is infinitely close.

The above time series prediction time model of landslide is obtained under ideal conditions, but in fact the model is limited by the interference caused by measurement error and equipment noise. In particular, the open-pit mine slope is usually affected by cyclical factors such as rainfall, groundwater, freeze-thaw of snow and ice, and artificial mining, etc. In this work, a mathematical model is built to eliminate engineering noise interference for landslide prediction, and noise is divided into the following two categories: (a) Instrumental noise (IN) of the measuring equipment, caused by the accuracy of the data collected by the equipment. (b) Environmental noise (EN) caused by environmental factors.

To avoid the dependence of single-point monitoring time series data and extract the periodicity of time as the feature, three smoothing filter algorithms are proposed to denoise the original velocity data. The 
three models are as follows. Short-period easy shifting filter (SSF): the speed is expressed as following $\mathrm{Eq}(6)$ :

$$
\bar{v}_{t}=\frac{v_{t}+v_{t-1}+\mathrm{L} v_{t-(\mathrm{n}-1)}}{n}
$$$$
n=3
$$

LSF model: the velocity is expressed as following Eq (6):

$$
\bar{v}_{t}=\frac{v_{t}+v_{t-1}+\mathrm{L} v_{t-(\mathrm{n}-1)}}{n}
$$

ESF model: the speeds are as follows.

$$
\bar{v}_{t}=\beta v_{t}+(1-\beta) \cdot \bar{v}_{t-1}
$$

The selection rules of the smoothing factor are as follows: The smoothing factor determines the smoothing level and the response speed to the difference between the predicted value and the actual result. The situation of the time series model of velocity multiplicative inverse element should be as stable and regular as possible, and the influence of the forward actual value on the fast smooth response degree and the slow smooth response degree of the predicted value should be avoided to the greatest extent, hence, the selection of smoothing factor $\beta=0.5$ is more appropriate.

This work draws on the noise reduction principle of monitoring equipment of the slope, respectively, to build the short-term noise reduction model ( $n=3$ day) and long-term noise model ( $n=7$ day). While satisfying the self-consistency of the stationarity and ergodicity in the time series model, the data collected are processed in accordance with this rule. At the same time, the maximum predictive benefit in predicting landslide accuracy is guaranteed when the velocity multiplication inverse velocity model is used again.

In addition, the landslide occurrence time can be further classified by using the landslide time prediction model based on gradient rate of change and the IVM model, which is mainly used to test the accuracy of 
the landslide time prediction model of time series using IVM model. In Fig. 7, a landslide time prediction model based on gradient rate of change is presented, and the concepts of safety and non-safety are expounded. $T_{f}$ represents the actual time of slope instability. $T_{f p}$ represents the predicted time of slope instability, and $t_{m}$ represents the time when the slope enters the acceleration stage. The $Y$-axis represents the expected excitation value of the predicted landslide, i.e., $t_{\mathrm{m}}\left(T_{f p}-t_{m}\right)$. The curve AB represents the true expectation of motivation. If the $T_{f p}$ at time $t$ happens to fall on the real excitation expectation line, then the predicted slope instability time $T_{f p}$ is equal to the actual slope instability time $T_{f p}$. If $T_{f p}$ at time $t$ falls just above the true expectation line, then the prediction result is not safe. That is, the $T_{f p}$ is greater than the $T_{f}$, indicating that the slope instability occurs before the predicted slope instability time $T_{f p}$, resulting in the site construction personnel and equipment cannot be evacuated and transferred in a timely manner. On the contrary, if $T_{f p}$ falls in the triangular regional $\mathrm{OAB}$, then the predicted results of the constructed model are safe, which allows the timely evacuation of equipment and personnel and the implementation of emergency plans before slope failure. The flowchart of landslide failure time prediction is shown in Fig. 8.

\subsection{Time forecast method and evaluation indexes selection of landslide}

Ground-based Synthetic Aperture Radar is used to monitor the deformation characteristics of the landslide, and its monitoring technology principle is shown in Fig. 8. Several distometric bases were put in place along the perimetral and recorded cumulative displacements since Janurary 1, 2013. Both measuring points were distributed near the tangential crack outcropping along the top, and the monitoring period was 1 January 2013 to April 17, 2013. Because the landslide is sudden type landslide, the characteristics of its velocity curve are quite different from the general three-stage evolution law of 
landslides. The initial period of constant velocity deformation is more lasting, and the curve morphology changes slowly. In other words, the landslide will remain relatively stable for a long time before the landslide, and there is no obvious macroscopic deformation sign. Instability failure can only occur when the landslide enters the critical kinetic failure stage. This makes Saito M's empirical prediction model limited, hence, it is necessary to seek for a more appropriate landslide time prediction model. The method adopted in this model is to select speed data for testing. Normally, in the process of slope acceleration, velocity, acceleration and displacement are three signals that represent the change of slope. According to previous research results, in the process of the dynamic evolution of landslide, especially near the slide acceleration as there will be a lag time than speed (Fig. 9), so the acceleration behavior may not be directly cause the deformation of slope failure factors. At the same time, displacement cannot describe the change process of slope on time scale, therefore, velocity data testing model is more suitable for this model.

\subsection{Selection method of Point OOA}

The first stage is defined from the beginning of the data collection point to the end of the initial attenuation stage. The authors select the OOA point according to the reference from the method proposed by Dick et al. 2015. From the initial attenuation stage (regression phase), the newly collected data is continuously fitted and modified until it approaches the value of 0 . That is, it can give the prediction decision for the landslide disaster prevention and control. The first stage of hierarchical early warning signals is divided into point OOA and point End of Acceleration (EOA). When the Point OOA is detected, the secondary attenuation stage (progressive stage) is found, and the linear recursive phase fitting calculation is performed from the trend point (TP). If the regression and progressive stages are not clearly 
divided, it can be understood as the point End of Acceleration (EOA), and the security signal is returned.

In this work, four smooth transition submodels of IVM are introduced, and the identification of OOA point needs to be based on the linear fitting accuracy from this point to the predicted landslide period.

\section{Analysis of forecast time of the open-pit mine landslide}

4.1 Performance of the model under the action of weak noise

Displacement data were extracted from the measuring points 515-3300, and the velocity raw data and displacement accumulation were shown in Fig. 10a. Landslide time prediction of time series of velocity data of measuring point 515-3300 using IVM models are shown in Fig. 11a. Figs. 10b and 10c showthat, when the landslide does not enter the acceleration stage, the velocity data after transformation shows a corrugated type and fluctuates up and down in a certain range. This model can detect speed outliers caused by instrumental noise and the environmental noise. However, when the landslide enters the acceleration starting stage, the velocity data after transformation gradually attenuates to zero and shows a linear expression of uniform trend distribution.

The landslide acceleration starting point (Trend Point) of the landslide is fitted linearly. The general global optimization algorithm is adopted in the fitting process. The method has the characteristic of independent of the initial value, and the calculation speed is faster and the solving precision is higher in the process of landslide time prediction fitting using IVM. The analysis process of each model is as follows.

(a) Raw data model

Take the measuring point 515-3300 with a large displacement variation as an example, the transformation results of raw data model is as shown in Fig. 11a. Fig. 10a shows that stage of 2013/01/01-2013/02/20 
has a large fluctuation, indicating that this stage is the initial attenuation stage (Regressive Stage). After 2013/02/20, the amplitude enters a relatively stable phase of further attenuation (Progressive Stage). The amplitude of oscillation in this stage is lower than that in the initial attenuation stage. Since 2013/04/01, the curve shows obvious linear characteristics. Fig. 11a shows that the predicted landslide time under the model is about 0.4 days earlier than the actual landslide time (i.e. $\Delta T=0.4$ Day), and the predicted time is basically consistent with each other, basically satisfying the predicted effect.

(b) SSF model

the transformation results of SSF model is as shown in Fig. 11b. Fig. 11b shows that in the stage 2013/01/01-2013/02/17, the amplitude of oscillation is relatively large, which indicates that this stage is the initial attenuation stage of the SSF model. The time for the displacement in under the SSF model, the time for the displacement to decay significantly and enter into a relatively stable decay phase was about three days earlier than that under the model with source velocity data. Through the comparison with the raw data and SSF model, the velocity data processed by SSF has good connectivity between the initial attenuation stage and the second attenuation stage, and the amplitude uniformity is relatively consistent. Since 2013/04/02, the slope has entered a significant linear change stage, that is, the slope has entered an acceleration stage. It can be seen from the curve characteristics that the SSF model, based on the raw data model, makes the ladder shape of the curve have an obvious tendency to eliminate, and the prediction effect is about 0.4 days in advance ( $\Delta T=0.4$ Day) (Fig. 11b). The prediction effect of SSF model is to make advance prediction before the actual time of landslide.

(c) LSF model

The transformation results of LSF model is shown in Fig. 11c. In phase of 2013/01/01-2013/02/26, the oscillation amplitude of the measured point data is relatively large, which is also the initial attenuation 
phase of the LSF model. The displacement in the LSF model attenuates significantly and enters a relatively stable attenuating phase, which are 6 and 11 days later than the Raw data model and the LSF model, respectively. The fluctuation boundary between the regressive stage and the progressive stage is also obvious. Under the LSF model, the curve shows that the slope has entered an obvious linear expression stage since 2013/04/05, which indicates that the slope has entered an acceleration stage. In terms of curve shape, LSF model presents a better fitting state based on raw Data model and SSF model respectively, but the landslide prediction time lags about 2.1 days (i.e. $\Delta T=-2.1$ Day) (Fig. 10c).

\section{(d) ESF model}

The transformation results of ESF model is shown in Fig. 11d. The phase of 2013/01/01-2013/02/26 is the regressive stage of ESF model. In the ESF model, the time to enter the relatively stable attenuation phase with a large displacement attenuation, which is 6 and 11 days later than that in the Raw data and SSF models, respectively, which is the same as in the LSF model. Under this ESF model, the curve shows that the slope has entered a significant linear change stage since 2013/04/05, that is, the slope has entered an acceleration stage. In terms of curve shape, compared with Raw data model, SSF Model and LSF model, the ESF Model has the lowest fitting accuracy, with a linear fitting correlation coefficient of only 0.86, but the predicted landslide time is consistent with the reality (i.e., $\Delta T=T a$ ) (Fig. 11d).

Fig. 12 shows the slope life expectancy curve under the four models. Except the ESF model, the curve morphology of the other models is approximate to the actual life expectancy time line in the slope failure process and converges in parallel. Fig. 12b shows that from 2013/04/10, the expected life expectancy curve of the slope is approximately the same as the actual life expectancy curve after the slope enters the acceleration stage. Fig. 12c shows that the slope life expectancy curve under LSF model intersects with the actual slope life expectancy curve in 2020/04/05, and finally deviates from the actual landslide time, 
presenting a delayed predictive expression effect. This indicates that the final prediction results show signs of lag outside the security range, and also verifies the accuracy of the fitting calculation results of LSF model. The slope life expectancy under ESF model is similar to the actual time, but compared with Raw data, SSF and LSF models, the slope life expectancy correlation curve has no obvious regularity.

4.2 Performance of the model under the action of strong noise

Landslide time prediction of time series of velocity data of measuring point 461-3250 using IVM is shown in Fig. 13. In the four models, the fluctuation and amplitude of the curve are large in the regressive stage. This is because the overlying strata in the goaf are disturbed by well mining near the open-pit mine landslide, and the slope is also disturbed by the open-pit mining cycle. The above two kinds of perturbations make the inverse velocity characteristic curve show obvious fluctuation characteristics. To explore the applicability of the IVM time prediction model of landslide under strong noise, the measuring point 461-3250 is taken as an example to test the model. The representation features of the four models are shown in Fig. 13, and the specific analysis process is as follows.

(a) Raw data model

Fig. 13a shows that the regressive stage is $2013 / 1 / 01-2013 / 2 / 22$. The progressive stage is $2013 / 2 / 22$ $2013 / 4 / 4$. It is noteworthy that the curve shape of the source velocity data presents a slightly concave shape from 2020/4/01 to 2020/4/11 (Fig. 13a). This is because of noise (disturbance of mining, disturbance of adjacent well construction, natural factors, etc.), resulting in no uniform change during the acceleration stage of the landslide. At the same time, although the landslide time prediction was brought forward by about 4.8 days ( $\Delta T=4.8$ Day), as shown in Fig.13a, since the slope data acquisition 
frequency unit of the open-pit mine is "day", the prediction value of landslide risk evaluation and anticipation of disaster prevention decision have to be too futuristic. This may cause economic loss to open-pit mine, so there is no clear guiding significance for the disaster prevention and mitigation of openpit mine landslide.

(b) SSF model

The data after the inverse velocity transformation using SSF model is shown in Fig. 13b. Fig. 13b shows that the regressive stage of the landslide evolution process was 2013/1/01-2013/2/23. The progressive stage is 2013/2/23-2013/4/4. Although fluctuation amplitude decreased in Regressive stage (with a range of $0 \sim 1.5 \mathrm{day} / \mathrm{mm})$, its oscillating patterns did not change significantly with SSF model treatment. In regressive stage, fluctuation shapes still showed an irregular trend. The specific performance was concentrated in the periods of 2013/01/06-2013/01/09, 2013/01/29-2013/02/05 and 2013/02/122013/02/19. It can be speculated that the fluctuation in this period is mainly influenced by Environment Noise. After the landslide enters the acceleration stage (namely the linear regression stage), the inverse velocity data processed by SSF model does not show good fitting ability.

(c) LSF model

The velocity raw data transformed by LSF model is shown in Fig. 13c. The period of 2013/01/012013/02/26 is the regressive stage. Compared with raw data and SSF models, the inverse velocity curve is smoother after using LSF model. In LSF model, the curve shows that the slope has entered a more significant linear regression stage since 2013/04/06, that is, the slope has entered an acceleration stage. Compared with the stepped curves of acceleration stage in Figs. 13a, b, c shows some degree of weakening and good smoothness. The landslide prediction time result obtained by using the LSF model is about 0.2 days before the actual landslide occurrence time ( $\Delta T=0.2$ Day) (Fig. 13c), which is more in 
line with the actual situation and has good prediction effect, and can be used as the decision reference for landslide prevention.

(d) ESF model

The inverse velocity curve of velocity raw data using ESF model is shown in Fig. 13d. The period of 2013/01/01-2013/02/26 is the regressive stage. The ESF model is similar to the regressive stage in the Raw data model. Although the amplitude of ESF model is large (0-1.4 day/mm), its smoothness is not well improved. Fig. 13d shows that ESF model is similar to LSF model, however, due to the smoothness of regressive smoothness and overall fitting of progressive stage is not ideal, therefore, the prediction performance of ESF model for noisy velocity data needs to be further improved.

The slope life expectancy curves of the four models are shown in Fig. 14. During 2013/04/01-2013/04/03, the slope life expectancy curve predicted by SSF and LSF models was approximately parallel to the actual life expectancy curve. Since 2013/04/09, that is, about one week before the actual occurrence of the landslide, the slope life expectancy curve of the prediction model using SSF and LSF models and the actual slope life expectancy curve have been approximately parallel convergence and coincidence convergence respectively. However, there is no coincidence between the prediction signal effect and the actual slope life expectancy curve in the end. The slope life expectancy curve predicted by ESF model intersects with the actual slope life expectancy curve on 2013/04/05/and 2013/04/11, and the predicted landslide time is not within the safe range. Compared with SSF, LSF and ESF models, the parallel convergence characteristics of the curves in the early stage of the acceleration phase of LSF model (2013/04/01-2013/04/10 period) are relatively regular. The predicted slope life expectancy curve and the actual slope life expectancy curve approximately produce a form of parallel convergence on 2013/04/10, and the two curves completely coincide on 2013/04/15, which also verifies the advance prediction result 
fitted by LSF model in the Progressive stage. Therefore, the prediction accuracy of LSF model for measuring points with high noise is relatively high.

\subsection{Performance of scale model with different displacement variation}

To explore the performance of the four models for landslide prediction at small velocity changes and the sensitivity identification of slopes at different stages of landslides evolution. Taking the measuring points 548-2200 and 461-3250 with small change of displacement as examples, the application analysis of the model is carried out. The velocity variation of the two points is shown in Fig. 15. Because the landslide is characterized by a sudden, the displacement change in the early stage of the landslide is not obvious, but when the landslide is about to happen, the displacement shows a sudden increase. To clearly analyze the difference between the two measurement points, the velocity curve during the accelerated start-up period was enlarged (Fig. 15). The corresponding variation range of measuring points 548-2200 and 4613250 was 0-50 mm/day and 0-240 $\mathrm{mm} /$ day, respectively. In the acceleration starting stage of the landslide, the velocity curve of the measured point 461-3250 shows an exponential trend, which indicates that the landslide bursting characteristics are more obvious. The velocity curve of measuring point 548-2200 presents a stepped form.

The inverse velocity curve of the measured point 548-2200 using the raw data model is shown in Fig. 16a. From 2013/01/01 to $2013 / 03 / 29$, regressive stage was used as the initial decay stage. With a relatively high rate of displacement change, the regressive stage lagged behind for about a month when compared with measurement point 461-3250. Since 2013/03/29, the inverse velocity curve entered the progressive stage with a reduced amplitude and a short duration. Since 2013/04/14, it has entered the stage of linear regression (i.e. the stage of continuous acceleration). Fig. 16a shows that although the 
predicted landslide time obtained using Raw Data model is 1.1 days earlier than the true time $(\Delta T=1.1$ Day). However, Fig. 16a shows that the prediction results of landslide time are not reliable because the correlation coefficient of curve fitting is 0.81 and the determination coefficient is 0.78 . Based on the above analysis of the measured point 548-2200 with small displacement variation, in the reciprocal representation method of time series velocity data. Fig. 16a shows that the initial regression stage of the measuring point 548-2200 has a longer time period, and the second decay stage and the linear regression stage define a shorter time period, in particular, the 2013/04/14-2013/04/17 is the linear recursion phase. This indicates that there are few data used to fit and solve landslide prediction time. Even if the prediction results are shown to be in advance, the verification results have a large error with the actual ones, and are not applicable to the open-pit mine.

(b) SSF model

Fig. 16b shows the inverse velocity curve after SSF model transformation. 2013/01/01-2013/03/31 is the Regressive Stage. Compared with raw data model, the time for SSF model to enter the progressive stage lags about two days. Since 2013/04/09, the slope has entered an obvious linear expression stage, which indicates that the slope has entered an acceleration stage. From the curve shape (Fig. 16b), the local fitting performance of SSF model for the accelerated curve is not ideal, which is similar to the analysis result using raw data model. The landslide prediction time is about 1.2 days in advance ( $\Delta T=1.2$ Day), and it has no guiding significance for landslide prediction.

(c) LSF model

Fig. 16c shows the inverse velocity curve using LSF model transformation. It can be found that the critical time between regressive stage and progressive stage is 2013/03/30, which lags about one day using SSF model. The fitting results of LSF model is shown in Fig. 16c. The correlation coefficient and 
determination coefficient of curve fitting are 0.96 and 0.78 , respectively. The prediction time of LSF model is 0.2 days earlier ( $\Delta T=0.2$ Day), which is close to the actual landslide time and more in line with the actual situation. Therefore, for the measuring points with small displacement variation, the fitting accuracy and predicted time performance of the LSF model are better and more in line with the reality.

(d) ESF model

The inverse velocity curve after EFS model transformation is shown in Fig. 16d. The prediction results of ESF model and LSF model are similar, and its prediction time is 0.4 days earlier ( $\Delta T=0.4$ Day).

Combined with the measuring point 548-2200 with a small displacement change and the point 461-3250 with a large displacement change, the landslide time prediction results of the two points were compared: When the displacement change is small, the prediction effect of the model on the boundary point between the initial regression stage and the second decay stage is not perfect, and there is a hysteresis effect. The raw data and SSF models were not ideal for the landslide acceleration phase when the four models were used for smooth transition. The applicability of the four models can be summarized as follows: when the velocity changes greatly, LSF model is recommended for landslide time prediction, while for short-term irregular data, while ESF model is recommended for landslide time prediction after data preprocessing. The accuracy and rationality of the calculated results are compared between the predicted and actual slope life expectancy. The predicted slope life expectancy curves of the four models and the actual slope life expectancy curves are shown in Figs. 17a-c shows that in the raw data model, the two curves show a parallel convergence trend since 2013/04/13, and the predicted slope life expectancy curve is about 0.8 days earlier than the landslide ( $\Delta T=0.8 \mathrm{Day}$ ), which is almost consistent with the fitting result (Fig. 17a). However, this prediction result is seldom used in training fitting data, and its verification results are difficult to be used as a reference for prediction. In SSF model, since 2013/04/10, the curves of the 
prediction model and the actual model converge approximately in parallel, which adds to the phenomenon of time lag in landslide prediction (Fig. 17b). In the LSF model, the curve has a special shape. Since 2013/04/06, the predicted life expectancy point of the slope is above the actual expected curve of the slope, and is defined as the danger range. In the period of 2013/04/07-2013/04/08, the line between the two expectation points in this stage is approximately parallel to the convergence of the actual slope life expectancy curve, but it is also above the actual slope expectation curve and is still defined as within the danger range.

\section{Discussion: Grading forecast of inverse velocity expression}

The landslide time prediction model based on IVM mainly determines the acceleration starting point (Trend Point) of landslide by transforming the slope velocity data, and then predicts the landslide time in the linear recursive stage. This method has the following advantages in combination with the open-pit mine landslide. For the original velocity data with obvious curve shape boundary, this method can be used to predict the landslide time, and the prediction accuracy and the fitting effect of linear regression stage are self-consistent. For sudden type landslides with large data noise, the moment of the initial acceleration stage of the landslide can be captured. The reliability of the models is affected by noise, and the application of SSF and LSF models is not clearly defined. The following is a comparative analysis of the applicability of the two models in the hierarchical prediction of inverse velocity expression.

\subsection{First order prediction}

Based on the above analysis, the LSF model has the defect of delayed prediction, while the SFF model is not sensitive enough to the noise change of velocity data. To avoid the shortcomings of the two models 
and give full play to their respective advantages in landslide time prediction, the expression mode of parallel intersection of the models was used to discuss. Specific methods and steps are as follows.

Combined with the monitoring data of LSF and SSF models, an example of measuring point 515-3300 was taken for analysis. The displacement variation and data form of the measuring point show great noise.

The intersection between a short - and long - term smooth movement is usually one of the most basic signals that indicate a trend change in the source velocity data. The speed curve processed by SSF model (gray curve) and LSF model (red curve) is shown in Fig. 18. The two curves show a cross shape. Based on the performance of long-term and short-term smooth prediction, the following assumptions are proposed: When the SSF model curve is interlaced with the LSF model curve at one point, after crossing the Crossover point, if the SSF model curve is on the LSF model curve, the time period is defined as the positive Crossover interval, namely, the positive Crossover point. Conversely, it is defined as a negative intersection.

Based on the above analysis, the long-term and short-term velocity data of monitoring point 515-3300 are analyzed. Taking 3 days as the time unit of short-term smooth transition, the velocity data is processed by short-term moving average. Taking 14 days as the time unit of long-term smooth transition, the longterm moving smooth filtering is performed on the velocity data. There is no standard range for the time interval of long-term and short-term smoothing. Different range of long-term and short-term smoothing will have different effects on the actual analysis and prediction results. According to the actual situation of the landslide (such as the acquisition frequency and displacement change rate of the monitoring equipment affected by mining disturbance, high noise level and other factors), the 3-day and 14-day moving period is more in line with the actual situation, and can make the short-term and long-term differences more obvious. The SSF model curve crossed with the SSF model curve for the first time on 
March 29, 2013; then, the two model curves showed an obvious downward trend, crossed for the second time on March 22, 2013, and then showed an upward trend in an approximate fitting shape; Combined with the actual situation, the second cross slope does not show obvious change, so the second cross point is regarded as the end point of the first acceleration. April 1, 2013 is the second intersection, which is the same as trend point (Fig. 18a).

Therefore, the analysis of the parallel use of SSF and LSF models has the following advantages: In the process of monitoring, when the two are positively crossed, the first threshold can automatically send signals. To some extent, it avoided the subjectivity of determining different observation points by experience, and increased the standardization of judgment of point OOA. If this method is applied to the radar monitoring of open-pit mines, it can theoretically provide reference for the dynamic evaluation of displacement change rate of multiple measurement points at the same time. It can then be extended to the risk assessment of landslide hazards, and the magnitude of regional instability can be estimated through multiple monitoring points distributed on a spatial scale. Finally, the identification signal of the acceleration phase is used to determine whether it is the local acceleration motion performance or the acceleration of all measuring points.

\subsection{Second order prediction}

To improve the reliability of the method in predicting landslide instability, the SSF and LSF models were used to transform the data suitable for the inverse velocity model in the first stage to obtain the best fitting curve. Since the prediction performance of the SSF and LSF models is different, they will get different landslide prediction time, and the difference between them is expressed as $\Delta$. The time scale predicted by the two models is assumed, namely, $T_{f(S S F)}<T_{f(L M A)}$; The window interval of landslide 
instability can be expressed as:

$$
\left[T_{f(S M A)}-\frac{\Delta}{2} ; T_{f(L M A)}+\frac{\Delta}{2}\right]
$$

In the prediction model, when the required test time $T>T_{f(S M A)}-\Delta / 2$ corresponds to the second-level activation cycle of landslide time prediction alarm. However, there are no clear rules for determining the limit value of the windowing parameter $T_{f w}$ using the established parameter $\Delta$; These parameters should be set according to the specific engineering application. In addition, in order to make the time covered by $T_{f w}$ long enough to consider the uncertainty in landslide time prediction, the boundary of detection failure time window should be widened, and the edge of the perimeter area is defined as $\Delta / 2$ at the same time. In particular, it avoids the inaccuracy of sending out the prediction signal in advance due to the premature activation of the second level prediction warning threshold. In the definition of $T_{f w}$, the assessment of landslide disaster risk factors and the specific characteristics of landslide emergency plan should also be considered. The grading prediction curve of the measuring point 515-3300 with low noise is shown in Fig. 18a. The model established a 5-day "time window" in 2013/04/15-2013/04/20. The actual landslide time was at $1 / 3$ of the interval $T_{f(S S F)}-T_{f(L M A)}$, which was located in the defined slope failure window. Slope failure "windowing" should be updated with collected data. By this method, the trigger time of landslide can be identified to a certain extent and the relevant decision plan can be adopted.

\section{Conclusions}

The landslide prediction model, method and application of open pit coal mine are studied, and some conclusions are obtained as follows.

1. The IVM is used to investigate the early warning and prediction of open-pit landslide, and the criterion of landslide instability is proposed. The IVM can be used as an effective tool to predict the landslide time, 
and the influence of other exogenous factors such as region, location and material properties on the model can be ignored in the prediction process. Based on the analysis results of the IVM and the kinematics characteristics of the landslide, the sliding deformation evolution process of the landslide is divided into three stages: the regressive stage, the progressive stage, and the autoregressive stage, that is, the initial deformation stage, accelerated deformation stage, and sliding instability stage. After the inverse velocity model is used to process the data, when the inverse velocity value continuously approaches 0 , it can be regarded as the predicted value of the occurrence time of landslide.

2. The accuracy of inverse velocity model prediction is closely related to the measured noise of the monitoring equipment and the natural noise of the environment. Two kinds of noise data may affect the inverse velocity model's recognition of different deformation stages. The four models of IVM are proposed to solve the above problem, including the raw data, SSF, LSF, and ESF models. The applicability of the four models in the early warning and prediction of open-pit mine landslide is compared and analyzed. Compared with Raw data and ESF models, the fitting effect of SSF and LSF was better when entering the linear autoregressive stage. By analyzing the inverse velocity curve shape, SSF and LSF models have different prediction performance.

3. OOA point is very important in IVM for landslide early warning and prediction, which is the boundary point to distinguish Regressive Stage and Progressive Stage. A slope displacement pixel difference method based on fitting accuracy and field monitoring signals is proposed to determine the point $00 \mathrm{~A}$.

On this basis, a hierarchical prediction method was proposed. The cut-off point of autoregressive stage in the inverse velocity model was used as the identification point of the first-level warning threshold, and was further defined by analyzing the intersection points of SSF and LSF. The second level demarcation point is defined by adding failure window. 
Han Du performed the data analyses and wrote the manuscript; Danqing Song helped perform the analysis with constructive discussions; Weiqiang Guo, Lihu Dong and Yukai Wang carried out subsequent field investigations.

\section{Declaration of competing interest}

The authors declare that they have no known competing financial interests or personal relationships that could have appeared to influence the work reported in this paper.

\section{Acknowledgments}

This study was supported by the China Postdoctoral Science Foundation (2020M680583), the National Postdoctoral Program for Innovative Talent of China (BX20200191), the Excellent Sino-foreign Youth Exchange Program of China Association for Science and Technology in 2020 (No. 58), and the Shuimu Tsinghua Scholar Program (2019SM058).

\section{References}

Admassu, Y., Shakoor, A., Wells, N.A., 2012. Evaluating selected factors affecting the depth of undercutting in rocks subject to differential weathering. Eng. Geol. 124, 1-11. https://doi.org/10.1016/j.enggeo.2011.09.007

Bozzano, F., Cipriani, I., Mazzanti, P., Prestininzi, A., 2014. A field experiment for calibrating landslide time-of-failure prediction functions. Int. J. Rock Mech. Min. Sci. 67, 69-77. 
Bozzano, F., Mazzanti, P., Prestininzi, A., Mugnozza, G.S, 2010. Research and development of advanced technologies for landslide hazard analysis in Italy. Landslides. 7 (3), 381-385. https://doi.org 10.1007/s10346-010-0208-X/

Carlà, T., Intrieri, E., Di Traglia, F., Nolesini, T., Gigli, G., Casagli, N., 2017. Guidelines on the use of inverse velocity method as a tool for setting alarm thresholds and forecasting landslides and structure collapses. Landslides. 14(2), 517-534. https://doi.org/10.1007/s10346-016-0731-5

Chen Z, Song, DQ, Hu C, Ke YT (2020) The September 16, 2017, Linjiabang landslide in Wanyuan County, China: preliminary investigation and emergency mitigation. Landslides 17(1):191-204. https://doi.org/10.1007/s10346-019-01309-1

Chen, M.X., Jiang, Q.H., 2020. An early warning system integrating time-of-failure analysis and alert procedure for slope failures. Eng. Geol. 272, 105629. https://doi.org/10.1016/j.enggeo.2020.105629

Chen, Z., Song, D.Q., 2021. Numerical investigation of the recent Chenhecun landslide (Gansu, China) using the discrete element method. Nat. Hazards. 105(1), 717-733. https://doi.org/10.1007/s11069-020$\underline{04333-w}$

Dick, G.J., Eberhardt, E., Cabrejo-Liévano, A.G., Stead, D., Rose, N.D., 2015. Development of an earlywarning time-of-failure analysis methodology for open-pit mine slopes utilizing ground-based slope stability radar monitoring data. Can. Geotech. J. 52(4), 515-529. https://doi.org/10.1139/cgj-2014-0028 Du, H., Song, D., Chen, Z., Shu, H., Guo, Z.Z., 2020. Prediction model oriented for landslide displacement with step-like curve by applying ensemble empirical mode decomposition and the PSOELM method. J. Clean Prod. 270:122248. https://doi.org/10.1016/j.jclepro.2020.122248

Fan, X.M., Domenech, G., Scaringi, G., Huang, R.Q., Xu, Q., Hales, T., Dai, L.X., Yang, Q., Francis, O., 2018. Landslides. 15(12), 2325-2341. https://doi.org/10.1007/s10346-018-1054-5 
592

593

594

Fukuzono, T., 1985. A new method for predicting the failure time of slopes. In: Japan Landslide Society Committee for International Exchange of Landslide Technique (ed) Proceedings of $4^{\text {th }}$ International Conference and Field Workshop on Landslides, Tokyo, Japan, 23-31 August, pp 145-150.

Gao, Y., Yin Y.P., Li, B., Feng, Z., Wang, W.P., Zhang, N., Xing, A.G., 2017. Characteristics and numerical runout modeling of the heavy rainfall-induced catastrophic landslide-debris flow at Sanxicun, Dujiangyan, China, following the Wenchuan MS 8.0 earthquake. Landslides. 14(4)1361-1374. https://doi.org/10.1007/s10346-016-0793-4

Haque, U., da-Silva, P.F., Devoli, G., Pilz, J., Zhao, B.X., Khaloua, A., Wilopo, W., Andersen, P., Lu, P., Lee, J., Yamamoto, T., Keellings, D., Wu, J.H., Glass, G.E., 2019. The human cost of global warming: Deadly landslides and their triggers (1995 - 2014). Sci. Total Environ. 682, 673 - 684. https://doi.org/ 10.1016/j.scitotenv.2019.03.415

He, L.P., Tan, J., Hu, Q.J., He, S.S., Cai, Q.J., Fu, Y.T., Tang, S., 2018. Non-contact measurement of the surface displacement of a slope based on a smart binocular vision system. Sensors. 18(9). 2890. https://doi.org/10.3390/s18092890

Kim, D.H., Gratchev, I., Balasubramaniam, A., 2015. Back analysis of a natural jointed rock slope based on the photogrammetry method. Landslides 12(1):147-154. https://doi.org/10.1007/s10346-014-0528-3 Liu, G.W., Song, D.Q., Chen, Z., Yang, J.W., 2020. Dynamic response characteristics and failure mechanisms of coal slopes with weak intercalated layers under blasting loads. Adv Civ Eng. 5412795. https://doi.org/10.1155/2020/5412795

López-Vinielles, J., Ezquerro, P., Fernández-Merodo, J.A., Béjar-Pizarro M., Monserrat, O., Barra, A., Blanco, P., García-Robles, J., Filatov, A., García-Davalillo, J.C., Sarro, R., Mulas, J., Mateos, R.M., Azañón, J.M., Galve, J.P., Herrera, G., 2020 Remote analysis of an open-pit slope failure: Las Cruces 
614

615

case study, Spain. Landslides. 17(9), 2173-2188. https://doi.org/10.1007/s10346-020-01413-7

Luzi, G., 2010. Ground based SAR interferometry: a modified tool for geoscience. In: Imperatore, P., Riccio, D. (Eds.), Geoscience and Remote Sensing, New Achievements, 978-953-7619-97-8. inTech Open Access Publisher, Rijeka, Croatia, pp. 1-26.

Ma, G.T., Hu, X.W., Yin, Y.P, Luo, G., Pan, Y.X., 2018. Failure mechanisms and development of catastrophic rockslides triggered by precipitation and open-pit mining in Emei, Sichuan, China. Landslides. 15(7), 1401-1414. https://doi.org/10.1007/s10346-018-0981-5

Mazzanti, P., 2011. Displacement monitoring by terrestrial SAR interferometry for geotechnical purposes. Geotech. Instrum. News 29 (2), 25-28.

Mufundirwa, A., Fujii, Y., Kodama, J., 2010. A new practical method for prediction of geomechanical failure. Int J Rock Mech Min Sci. 47(7), 1079 - 1090. https://doi.org/10.1016/j.ijrmms.2010.07.001

Osasan, K.S., Stacey, T.R., 2014. Automatic prediction of time to failure of open pit mine slopes based on radar monitoring and inverse velocity method - sciencedirect. Int. J. Min. Sci. Tech. 24( 2), 275-280. http://dx.doi.org/10.1016/j.ijmst.2014.01.021

Rose, N.D., Hungr, O., 2007. Forecasting potential rock slope failure in open pit mines using t he inverse-velocity method. Int. J. Rock Mech. Min. Sci. 44(2), 308-320. https://doi.org/10.1016 /j.ijrmms.2006.07.014

Severin, J., Eberhardt, E., Leoni, L., Fortin, S., 2014. Development and application of a pseudo-3d pit slope displacement map derived from ground-based radar. Eng. Geol. 181, 202-211. https://doi.org/ 10.1016/j.enggeo.2014.07.016

Song, D.Q., Chen, Z., Ke, Y.T., Nie, W., 2020a. Seismic response analysis of a bedding rock slope based on the time-frequency joint analysis method: a case study from the middle reach of the Jinsha River, 
China. Eng. Geol. 274, 105731. https://doi.org/10.1016/j.enggeo.2020.105731

Song, D.Q., Liu, X.L., Chen, Z., Chen, J.D., Cai, J.H., 2020b. Influence of Tunnel Excavation on the Stability of a Bedded Rock Slope: A Case Study on the Mountainous Area in Southern Anhui, China. KSCE J. Civ. Eng. 25(1), 114-123. https://doi.org/10.1007/s12205-020-0831-6

Song, D.Q., Liu, X.L., Huang, J., Wang, E.Z., Zhang, J.M., 2020d. Characteristics of wave propagation through rock mass slopes with weak structural planes and their impacts on the seismic response characteristics of slopes: a case study in the middle reaches of Jinsha River. Bull. Eng. Geol. Environ. 80(2), 1317-1334. https://doi.org/10.1007/s10064-020-02008-1

Song, D.Q., Liu, X.L., Huang, J., Zhang, J.M., 2020c. Energy-based analysis of seismic failure mechanism of a rock slope with discontinuities using Hilbert-Huang transform and marginal spectrum in the time-frequency domain. Landslides. 18(1), 1-19. https://doi.org/10.1007/s10346-020-01491-7

Song, D.Q., Liu, X.L., Li, B., Zhang, J.M., Bastos, J.J.V., 2020e. Assessing the influence of a rapid water drawdown on the seismic response characteristics of a reservoir rock slope using time-frequency analysis. Acta Geotech. 1-22. https://doi.org/10.1007/s11440-020-01094-5

Tarolli, P., Sofia, G., 2016. Human topographic signatures and derived geomorphic processes across landscapes. Geomorphology. 255, 140-161. https://doi.org/10.1016/j.geomorph.2015.12.007

Tommaso, C., Paolo, F., Emanuele, I., Kostas, B., Nicola, C., 2017. On the monitoring and early-warning of brittle slope failures in hard rock masses: examples from an open-pit mine. Eng. Geol. 228, 71 - 81.

Ventura, G., Vinciguerra, S., Moretti, S., Meredith, P.H., Heap, M.J., Baud, P., Shapiro, S.A., Dinske, C., Kummerow, J., 2009. Understanding slow deformation before dynamic failure. In: Tom Beer (ed) Geophysical Hazards, 1st edn. Springer Netherlands, pp. 229-247.

Voight, B., 1989. A relation to describe rate-dependent material failure. Science 24(3),200-203. 
659

660

661

662

663

664

665
Wu, J.H., Lin, W.K., Hu, H.T., 2018. Post-failure simulations of a large slope failure using 3DEC: the

Hsien-du-shan slope. Eng. Geol. 242, 92-107. https://doi.org/10.1016/j.enggeo.2018.05.018

Zare Naghadehi, M., Jimenez, R., Khalokakaie, R., Esmaeil Jalali, S., 2013. A new open-pit mine slope instability index defined using the improved rock engineering systems approach. Int J Rock Mech Min Sci. 61,1-14. http://dx.doi.org/10.1016/j.ijrmms.2013.01.012

Zhou, X.P., Liu, L.J., Xu, C., 2020. A modified inverse-velocity method for predicting the failure time of landslides. Eng. Geol. 268, 105521. https://doi.org/10.1016/j.enggeo.2020.105521 


\section{Figures}
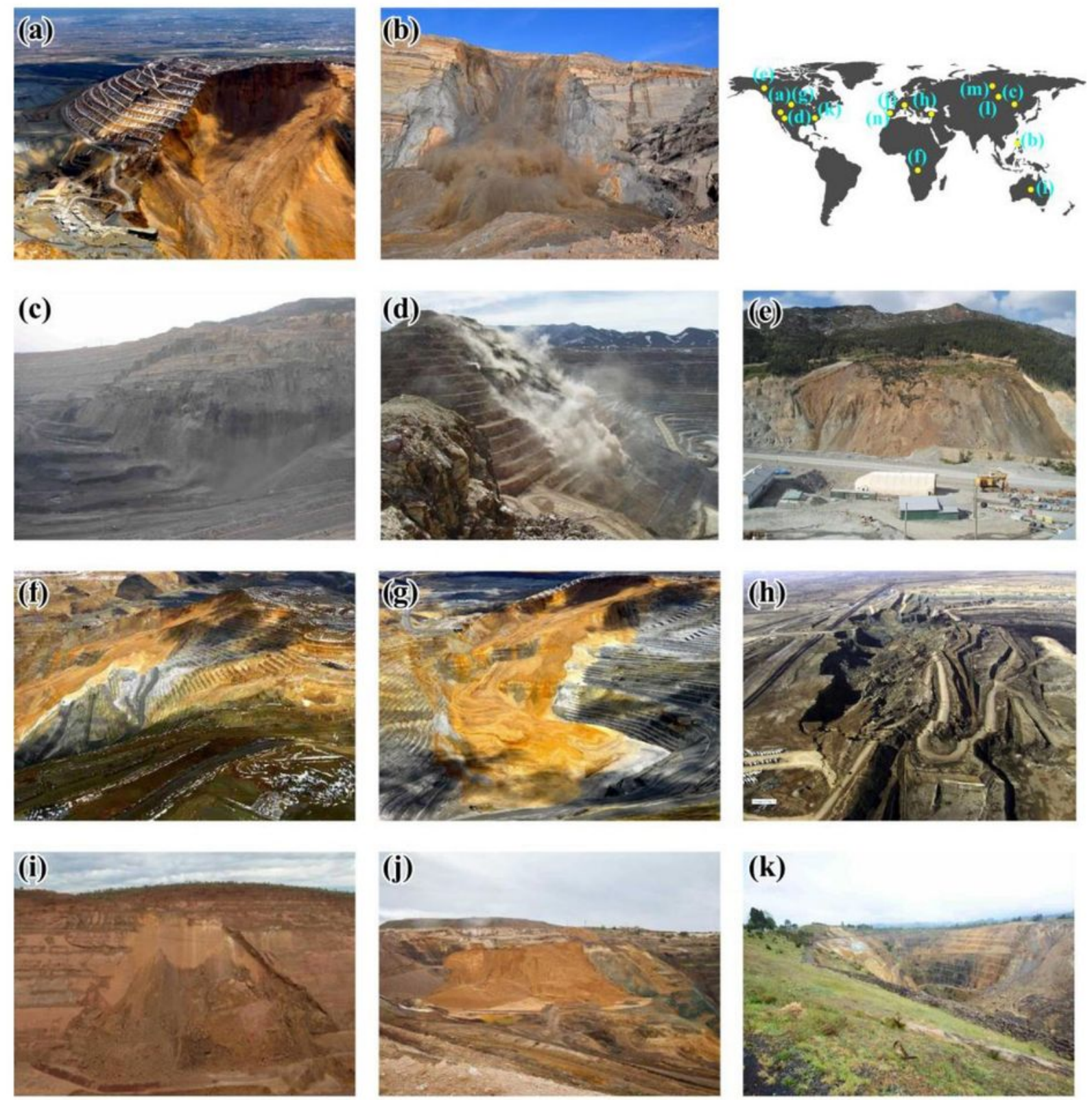

(k)
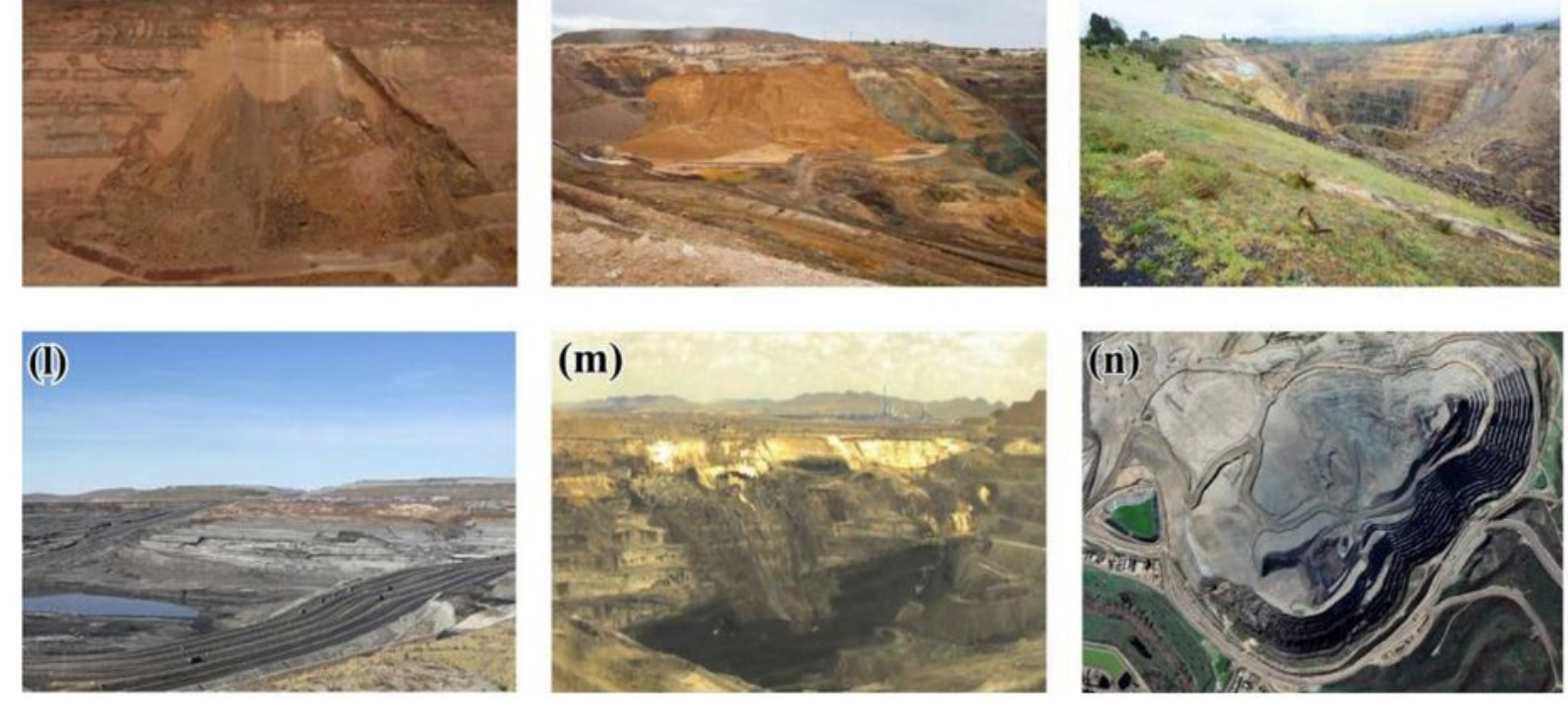

\section{Figure 1}

Worldwide surface mining landslide disastrous events from Google Retrieval and related literatures: (a) Bingham Canyon Mine, Utah, United States (Moore et al. 2016); (b) Panian Open Pit, Caluya, Philippines(https://blogs.agu.org/landslideblog/); (c) West Open Pit, Chifeng, China (Xiao 2014); (d) 
Betze-Post Gold Mine, Nevada, United Stat-es (https://blogs.agu.org/landslideblog); (e) Huckleberry Mine, Smithers British Columbia, Canada (https://blogs.agu.org/landslideblog/); (f) Australia; (g) Utah Copper Mine, Utah, United States (Pankow et al. 2013); (h) Çöllolar open pit mine, Elbistan Turkey(Akcar et al. 2019); (i) West Angles Centre Pit North, Australia (Venter et al. 2013); (j) Sk-ouriotissa Mines, The Republic of Cyprus (https://www.visitsolea.com/skouriotissa-mines/); (k) Longwall mines, U-nited States (Behrooz 2016); (I) Baiyinhua Open Pit Mine, China(Du 2017); (m) Shengli East Open-Pit Mine, Xilinhot, China (Liu et al. 2020); (n) Las Cruces Open-pit Mine, Seville, Spain (Juan et al. 2020)

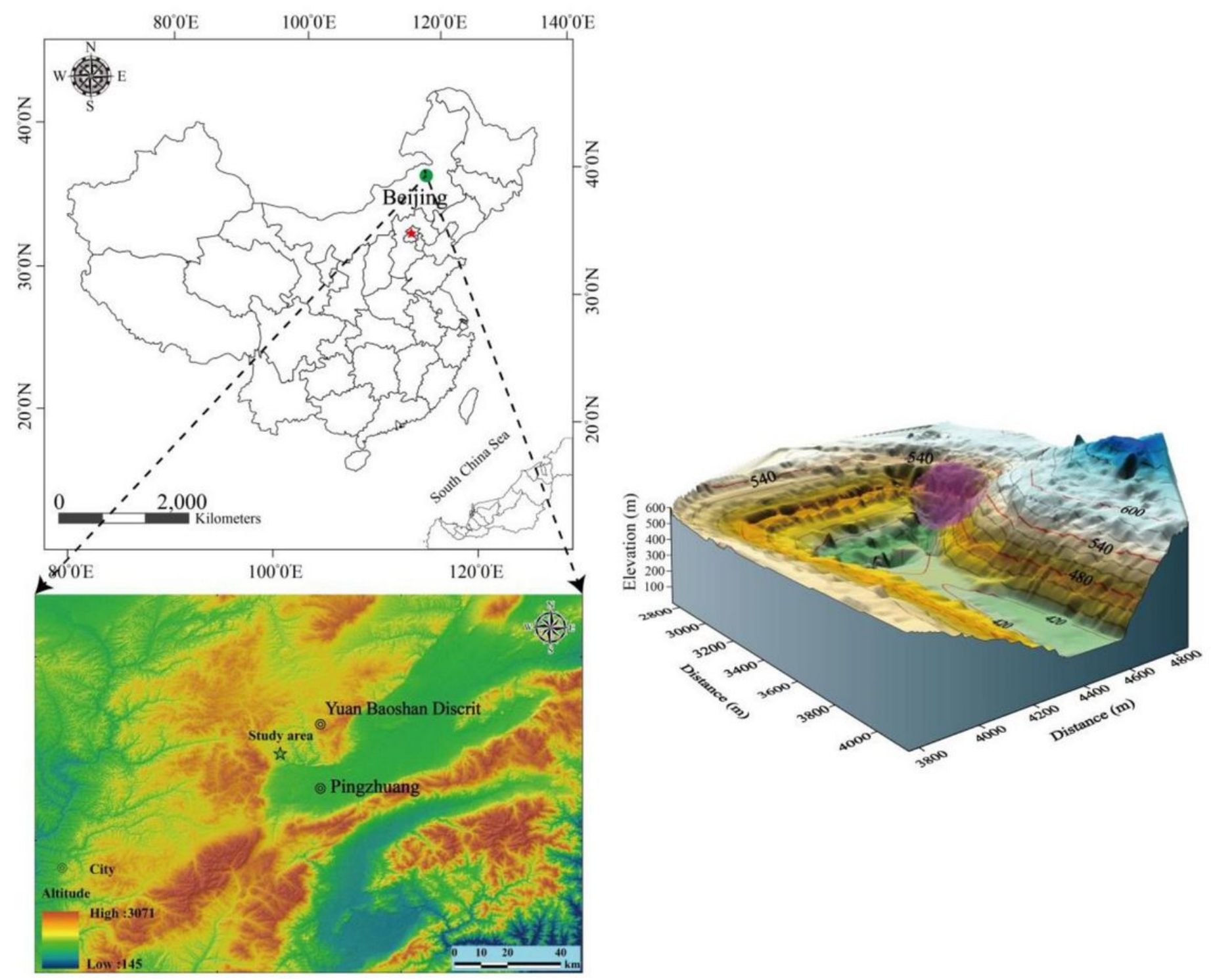

Figure 2

Location of the Pingzhuang west open-mine landslide, Inner Mongolia, China 


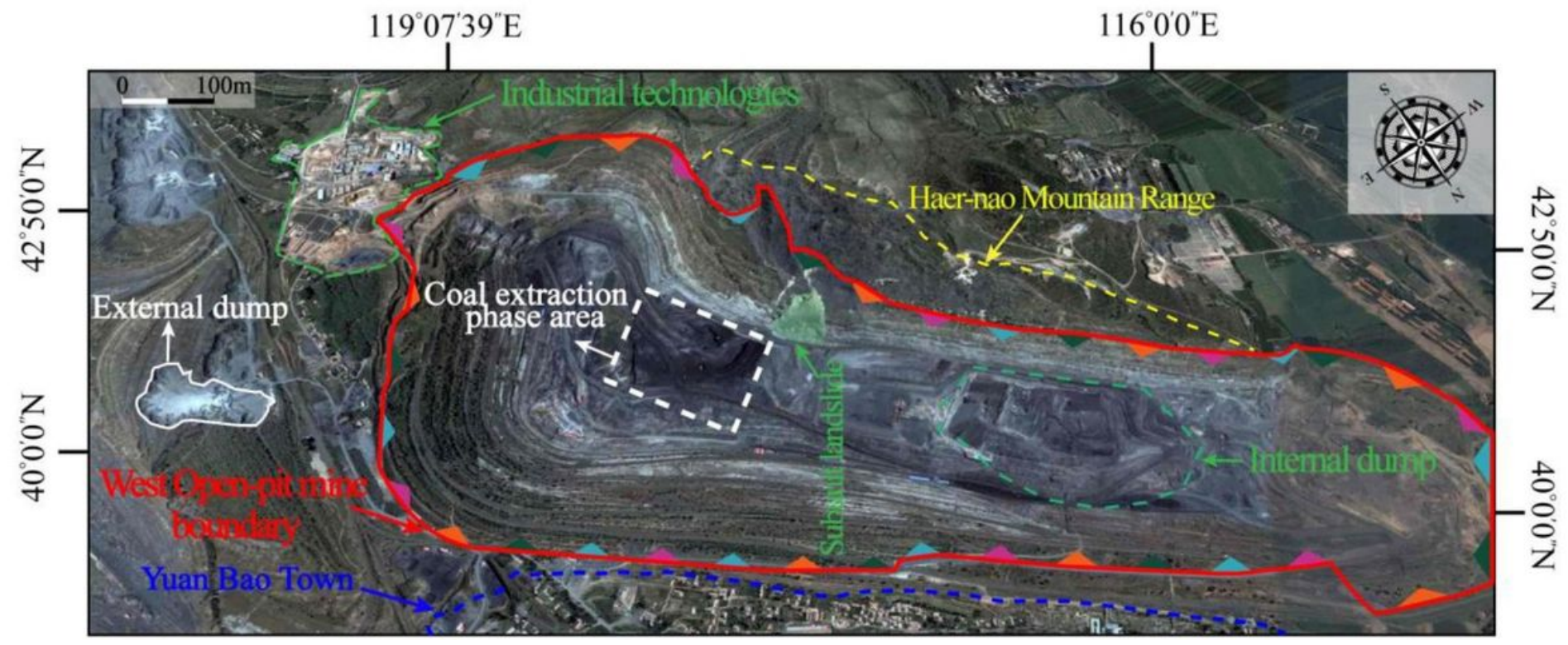

Figure 3

Orthoimage of Pingzhuang West Open-pit Mine 

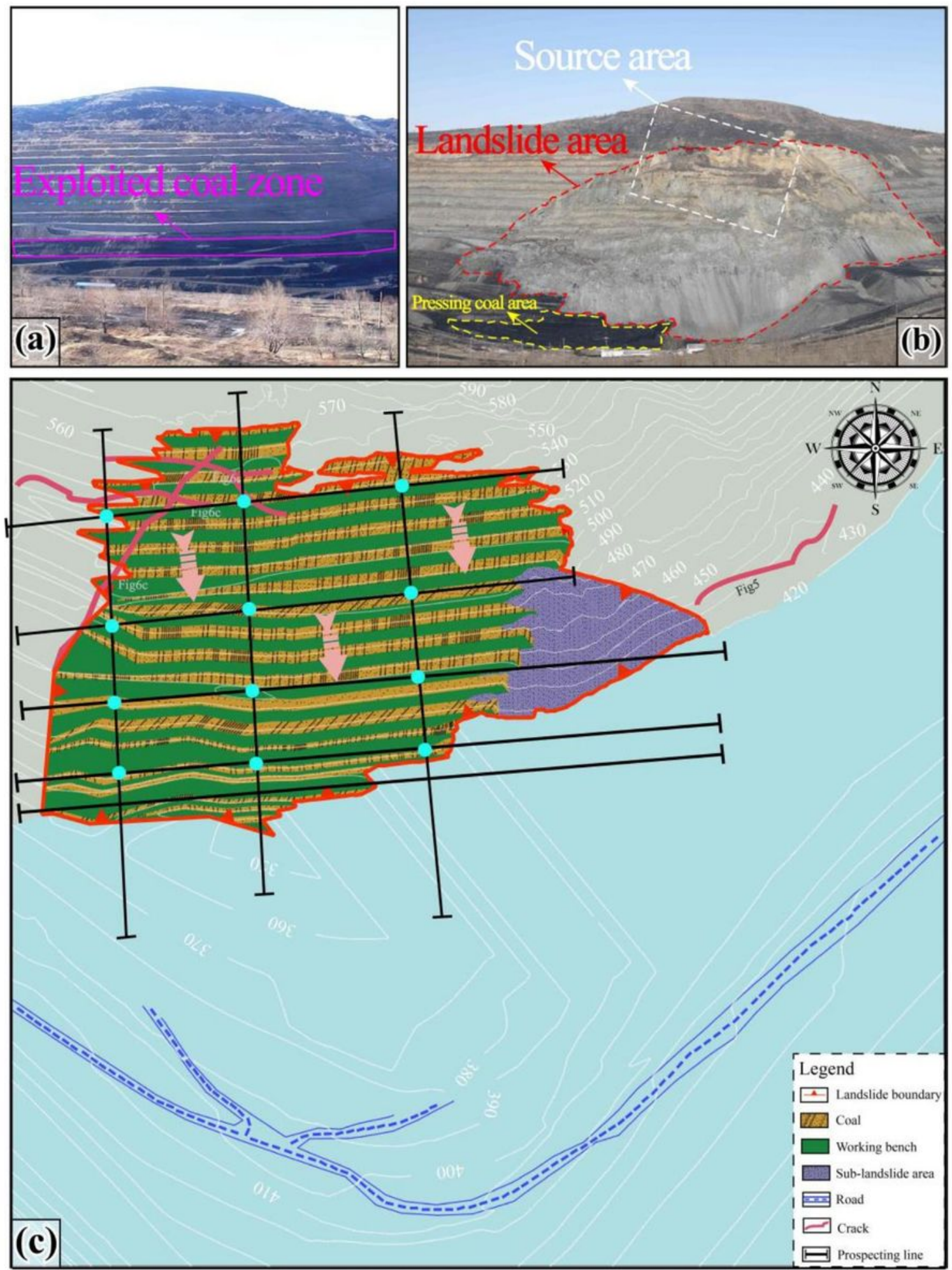

Figure 4

Landform and diagram of the open-pit mine landslide: (a) Front view of the slope pre sliding; (b) Front view of after landslide; (c) Planar map of the landslide. 


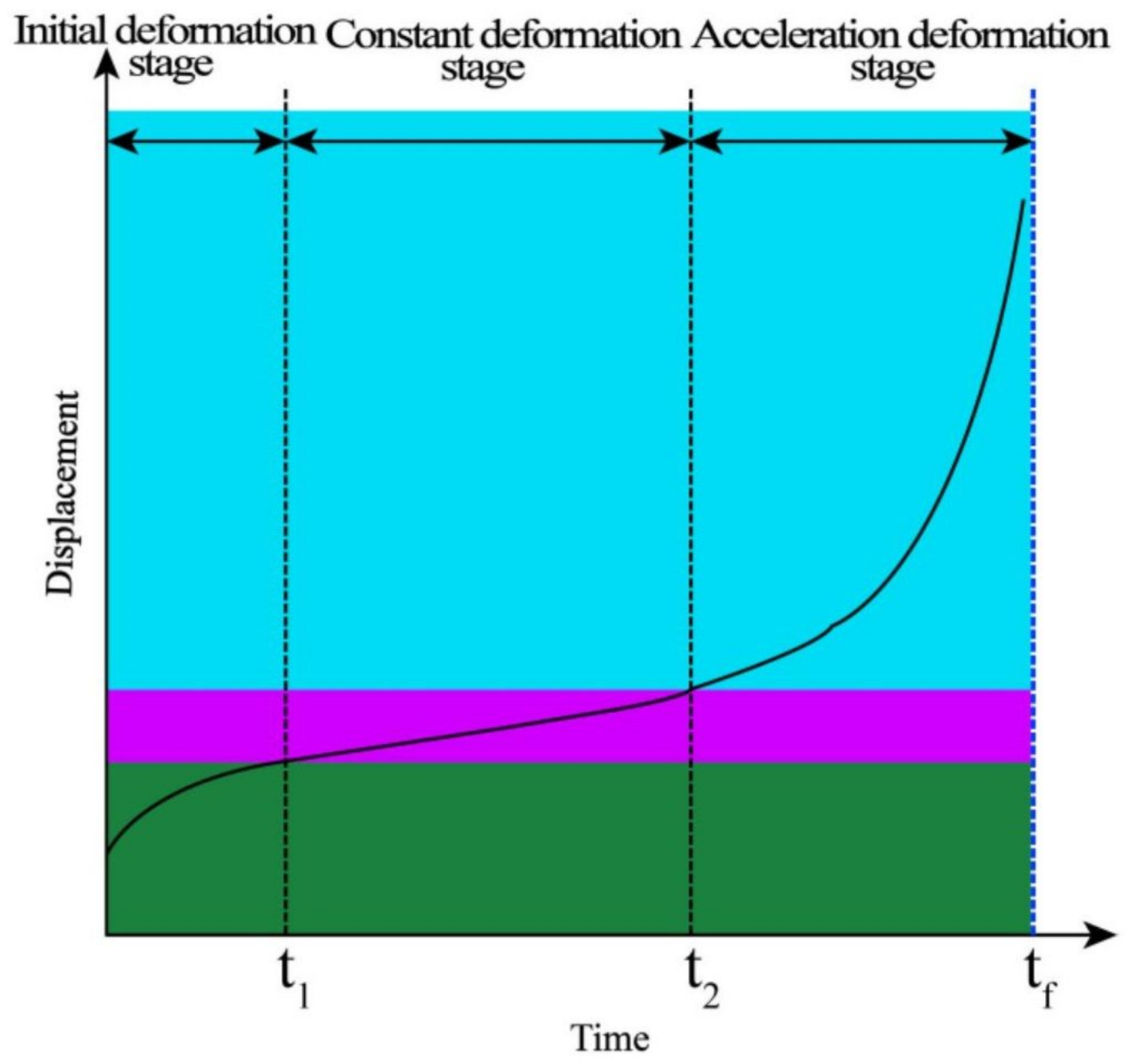

Figure 5

Diagram of three stages of landslide creep 


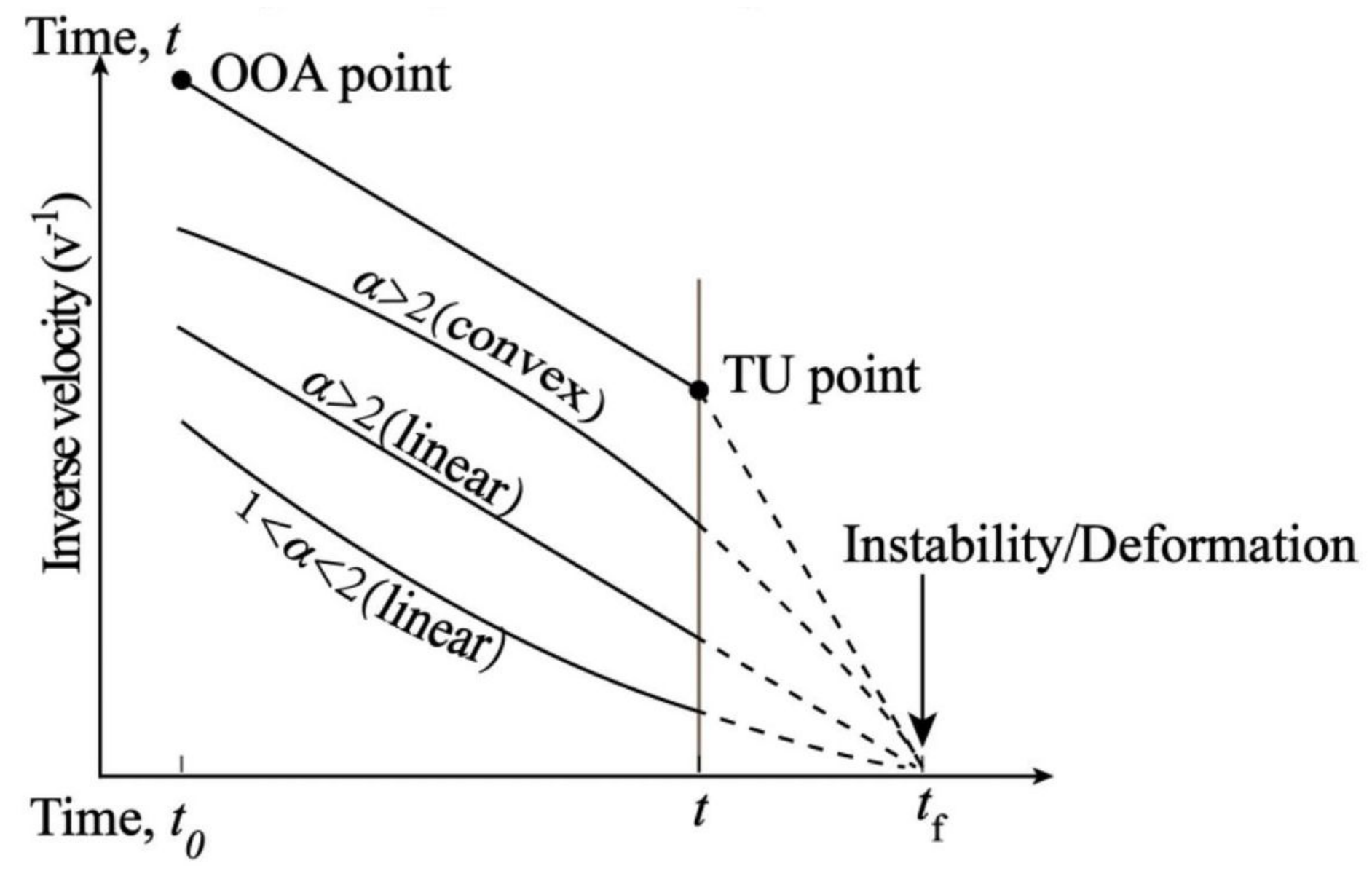

Time

Figure 6

Schematic diagram of conventional inverse velocity method (modified after Chen and Jiang 2020). OOA is the onset of acceleration and TU is the trend update point. 


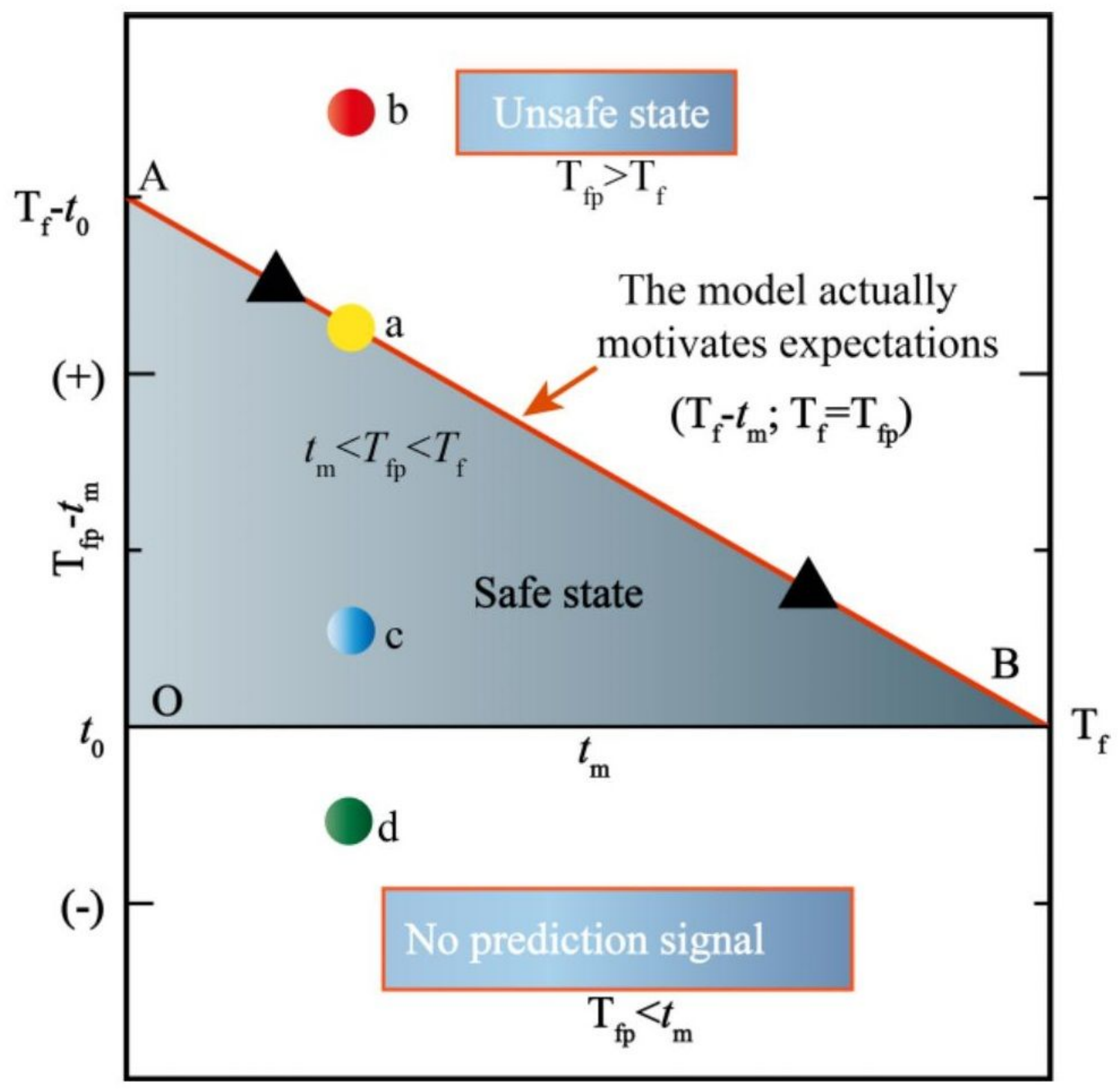

Figure 7

A basic theoretical model representing predicted life expectancy (Tfp-tm) as a operation of tm (time at instant of predicting) as failure-time $\mathrm{Tf}$ methods. Attention: $\mathrm{t0}$ is initial arbitrary time representing commencement of prediction and $\mathrm{Tf}-\mathrm{t} 0$ is initial actual life expectancy. 


\section{Data monitoring and processing}
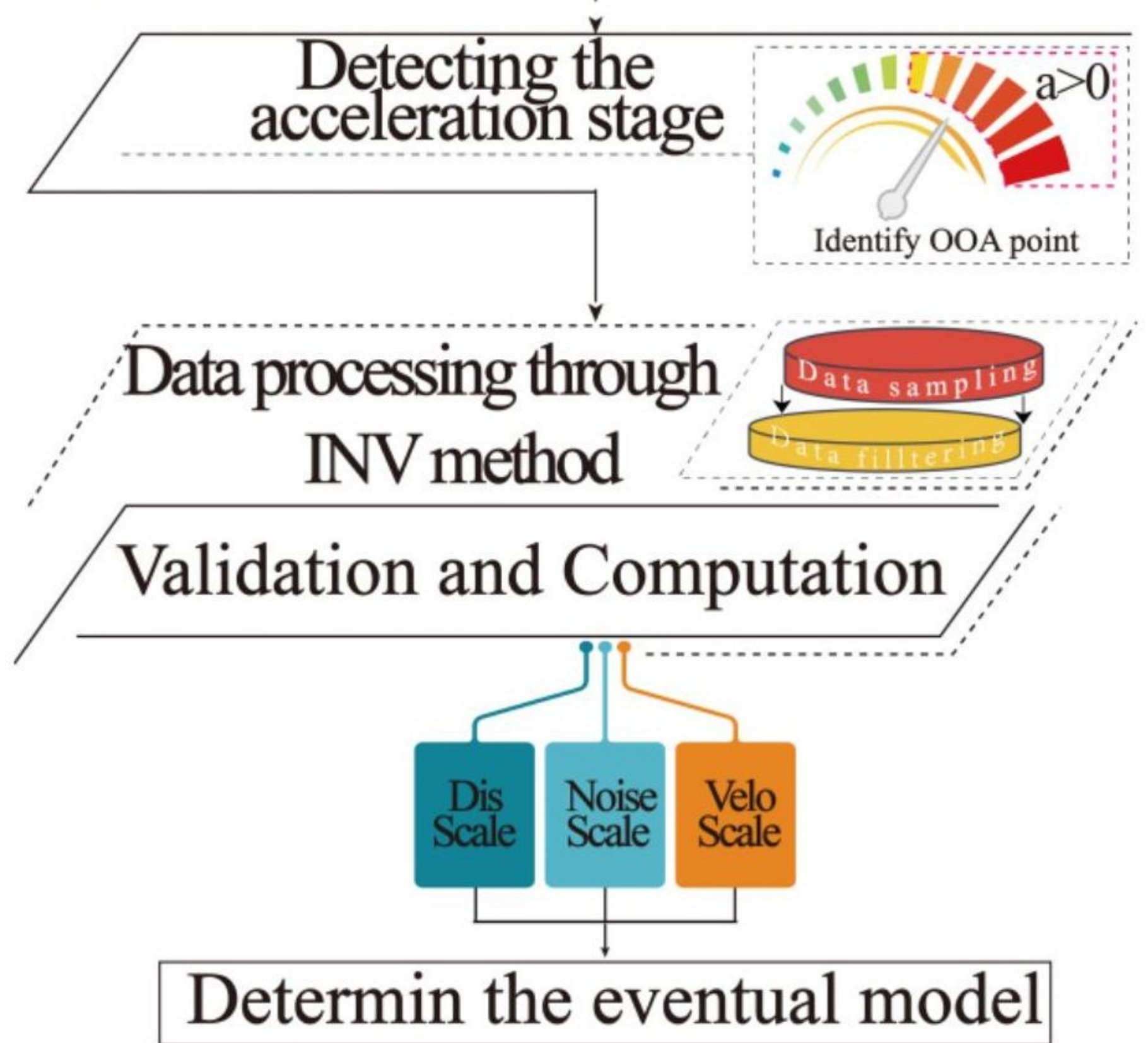

Figure 8

Flowchart for the real-time time-of-failure analysis methodology 


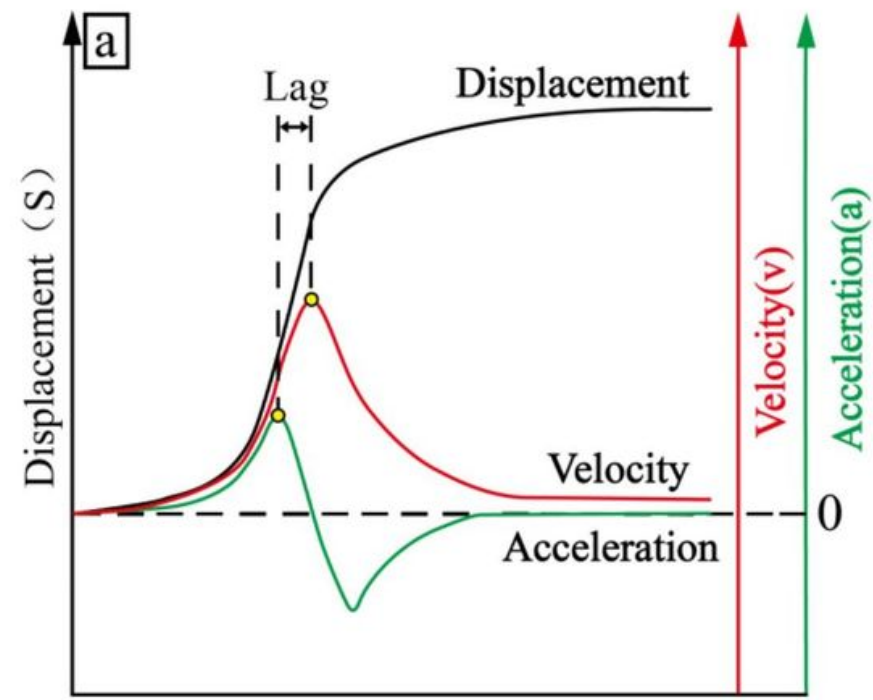

Time,t

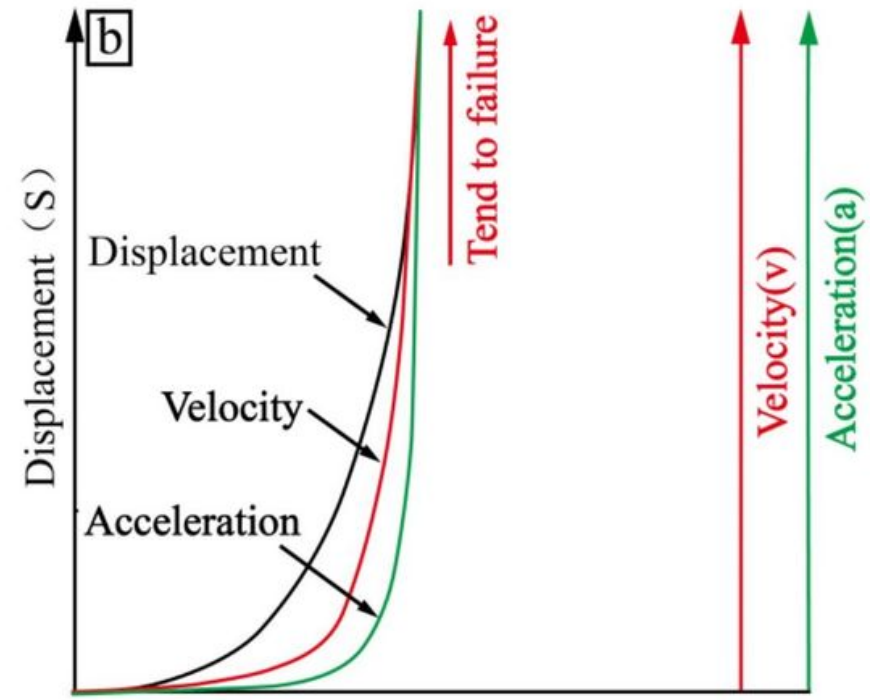

Time,t

Figure 9

Schematic diagram of the relationship between displacement (S), velocity (v) and acceleration (a).

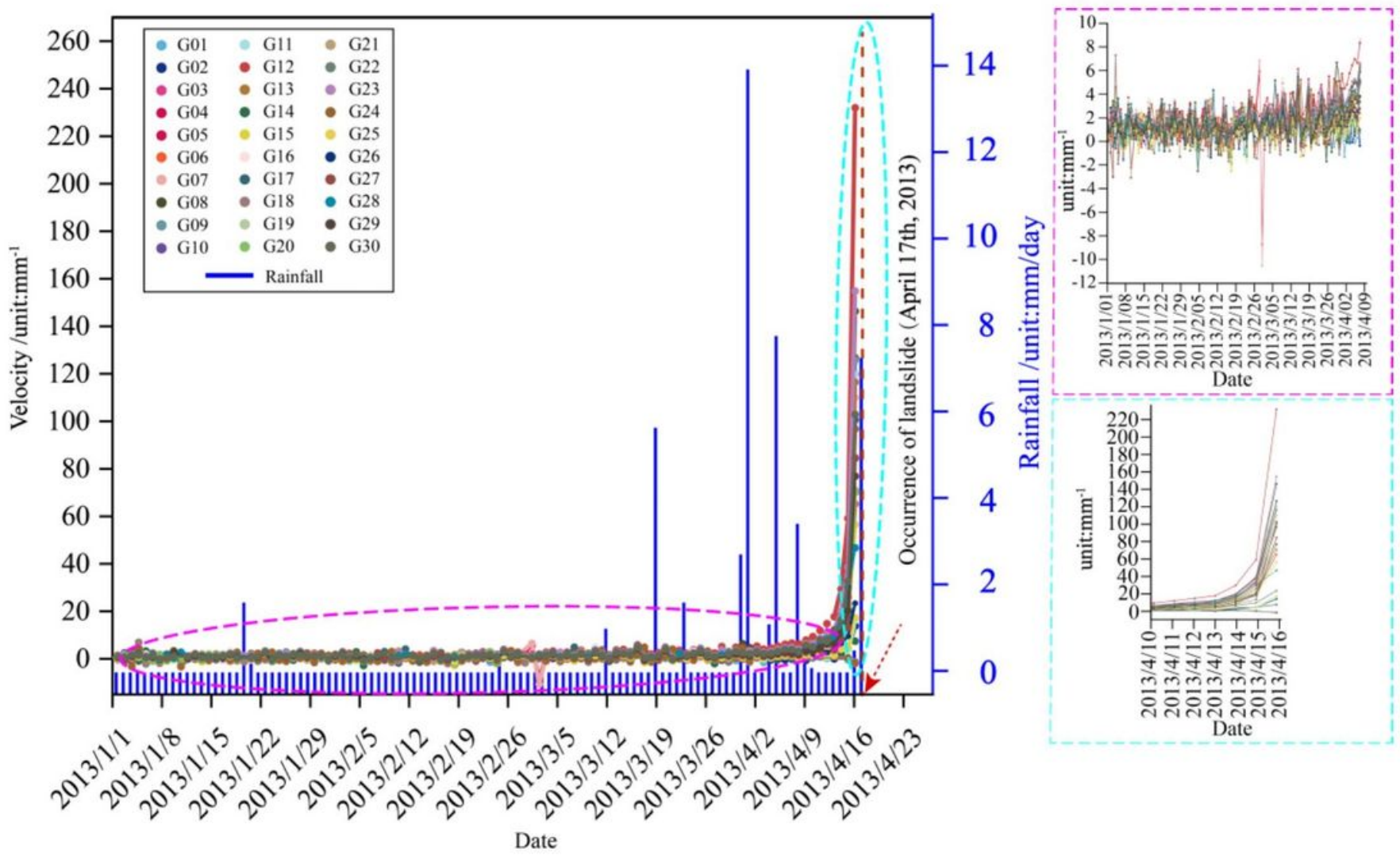

Figure 10

Velocity dataset and daily precipitation (grey) recorded at the Pingzhuang 4.17 landslide. 

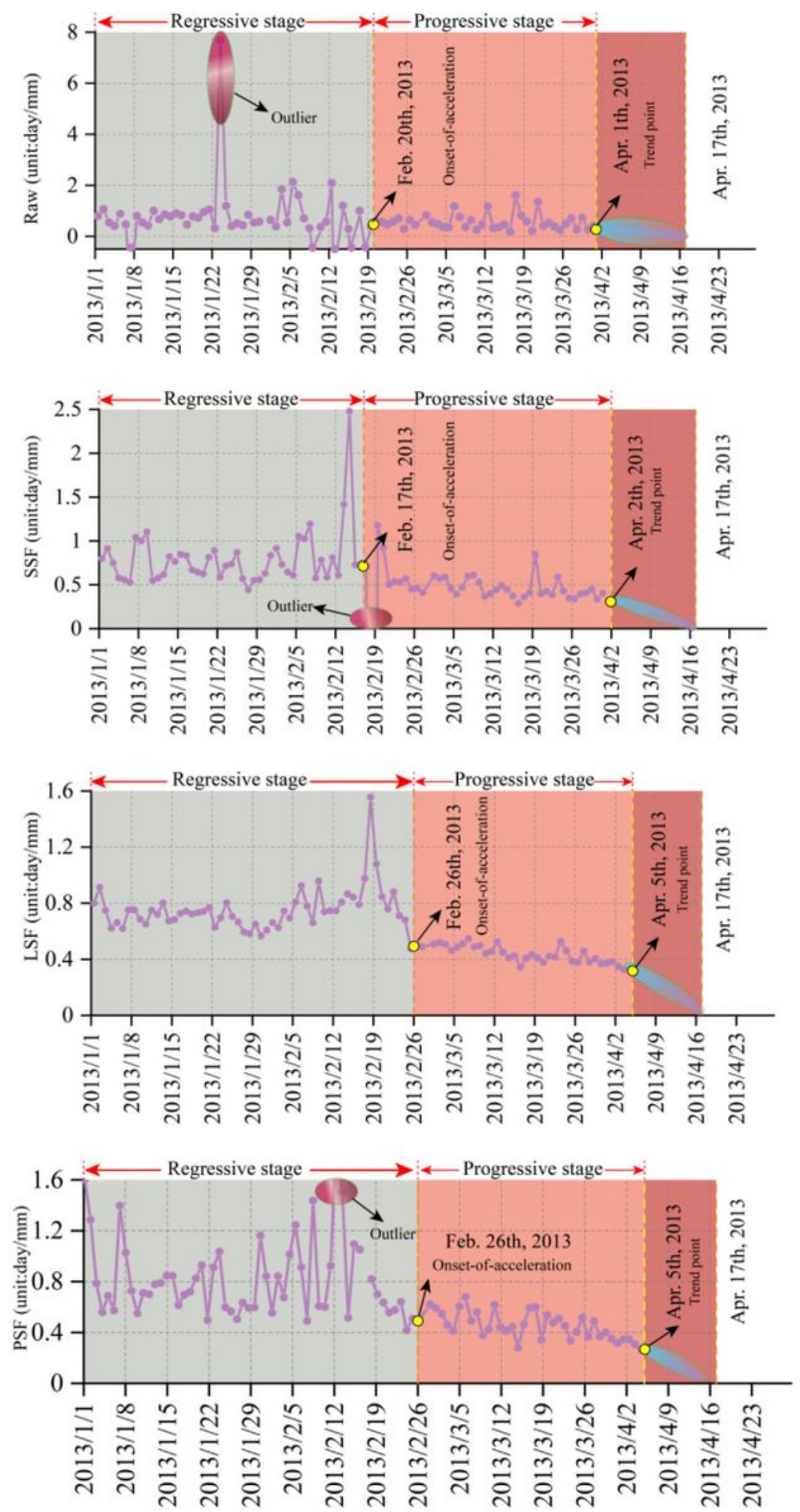

Figure 11

The representation method of landslide time prediction under inverse meta-model of velocity data multiplication 


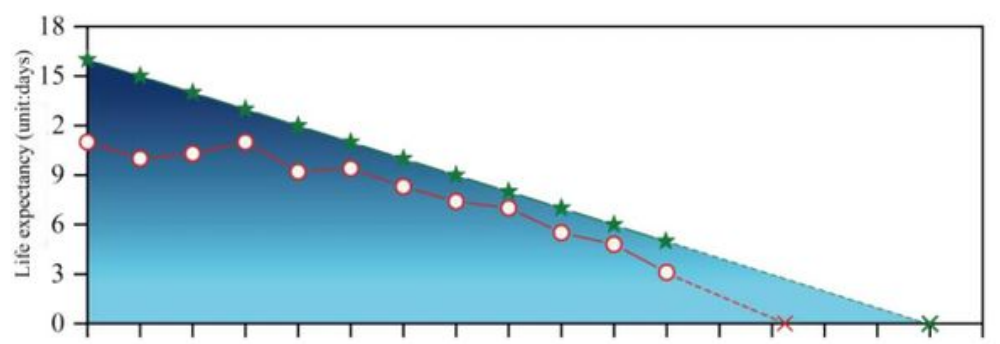

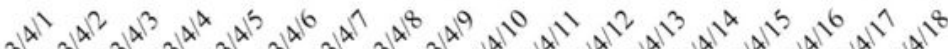

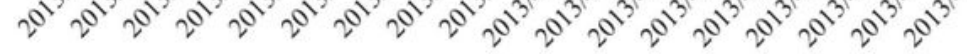

(a)
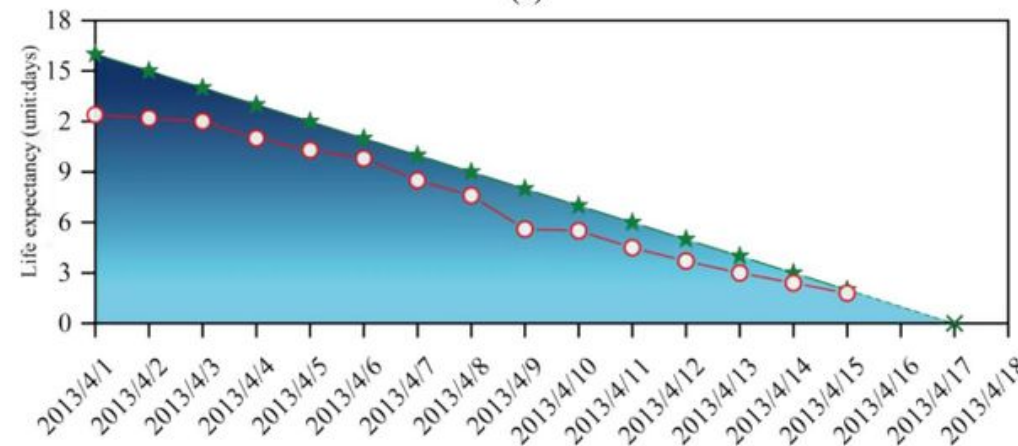

(b)
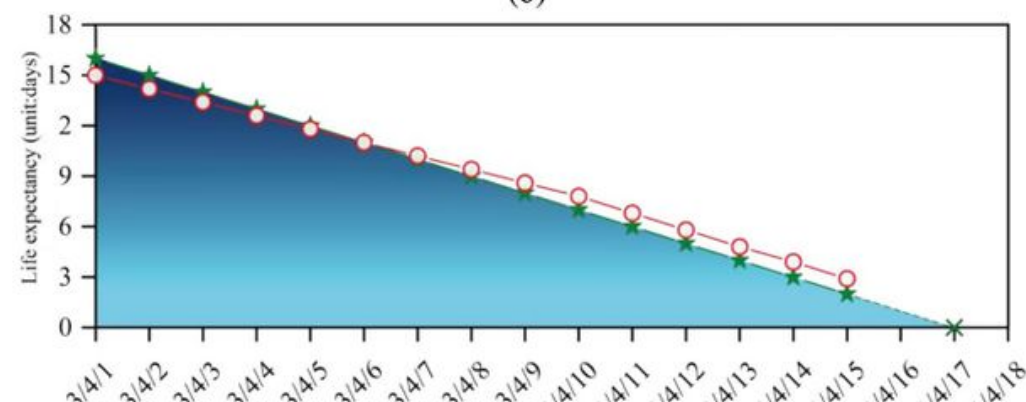

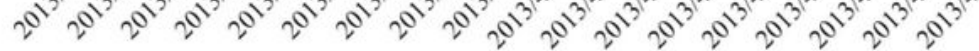

(c)

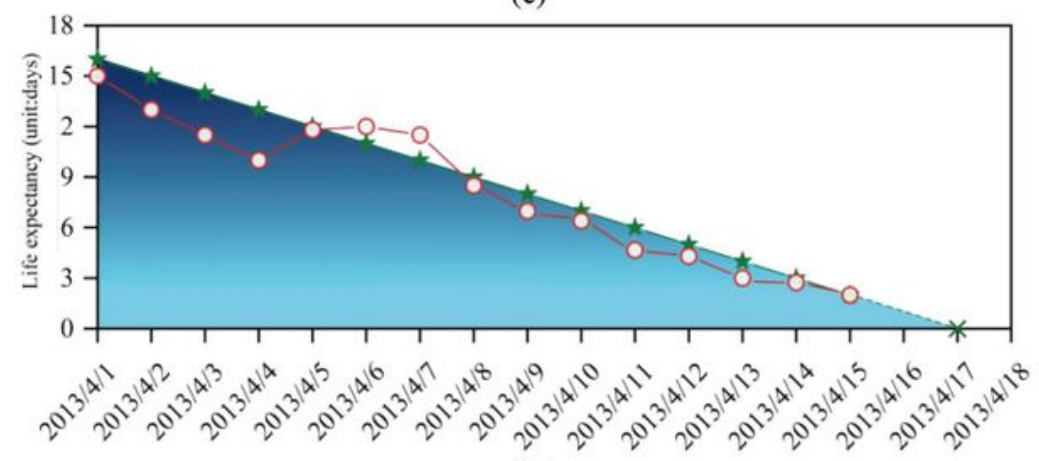

(d)

Figure 12

Life expectancy of Monitoring point 3300 in elevation 515 

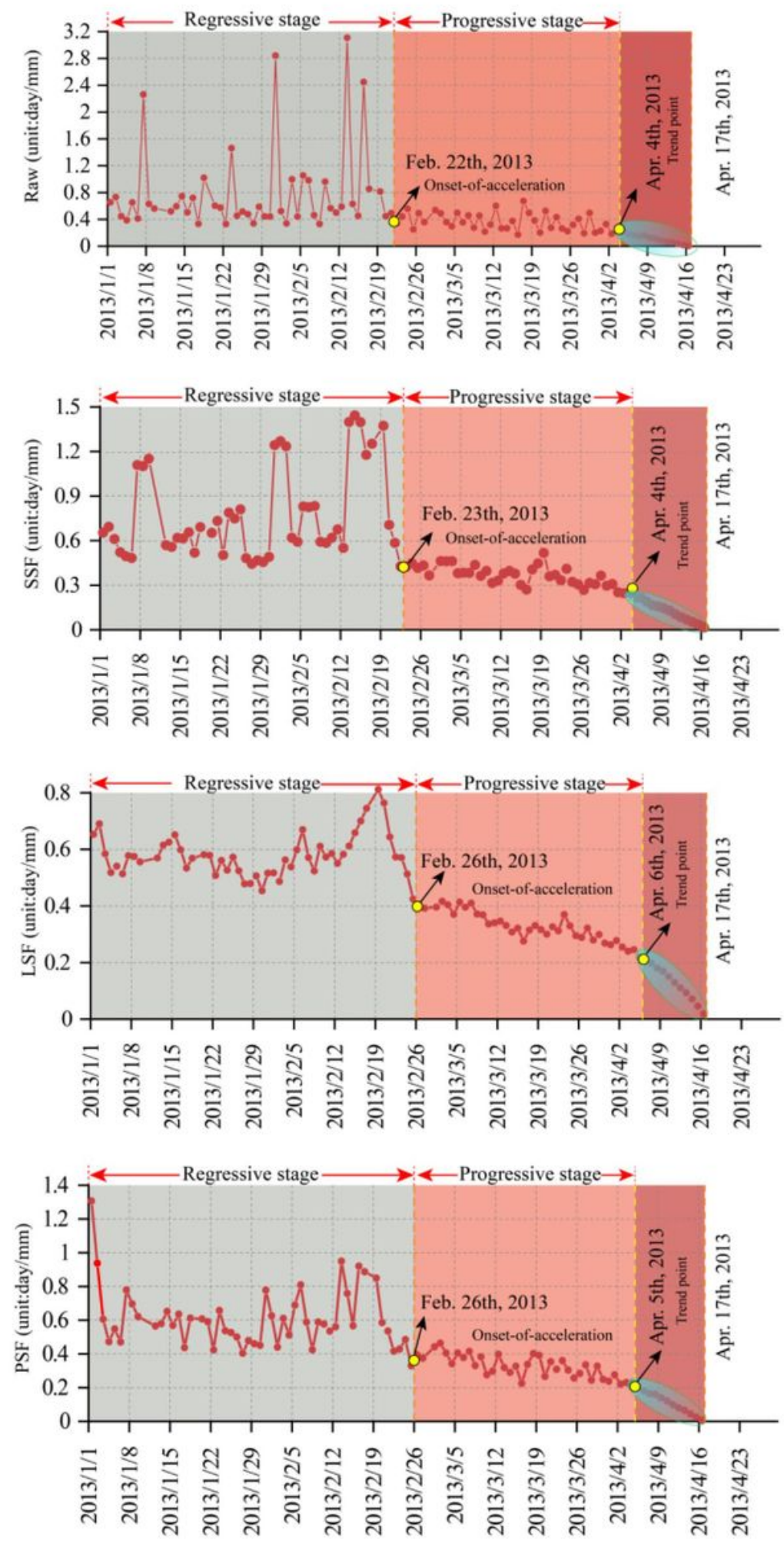

\section{Figure 13}

Schematic diagram of landslide time prediction based on reciprocal velocity data of 461-3250 time series model at monitoring points (a) Raw Data; (b) SSF; (c) LSF; (d) ESF. 

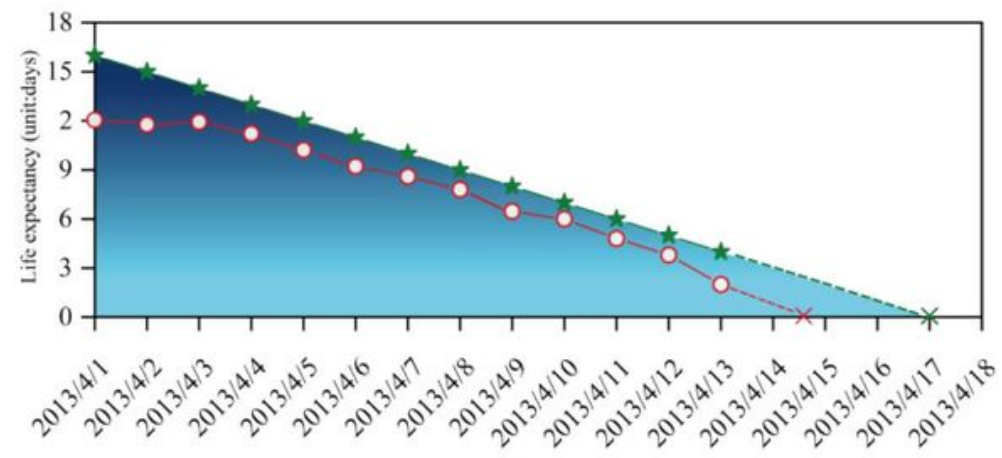

(a)
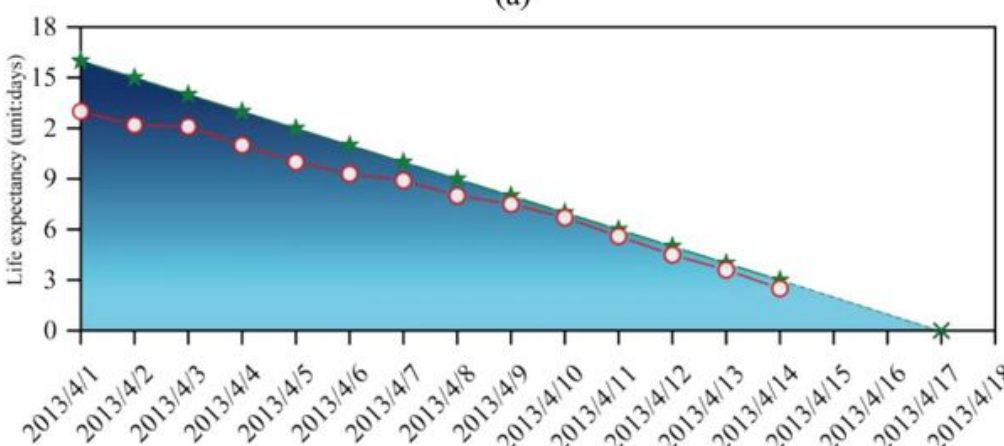

(b)
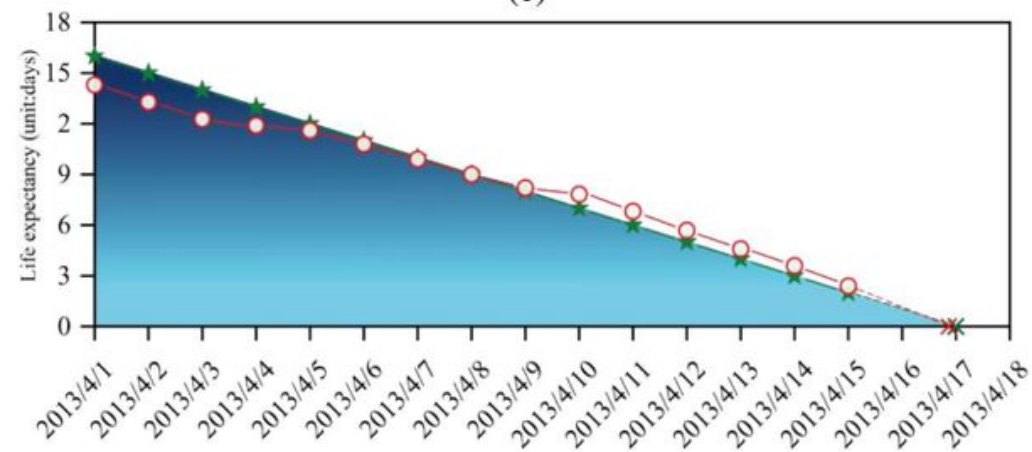

(c)

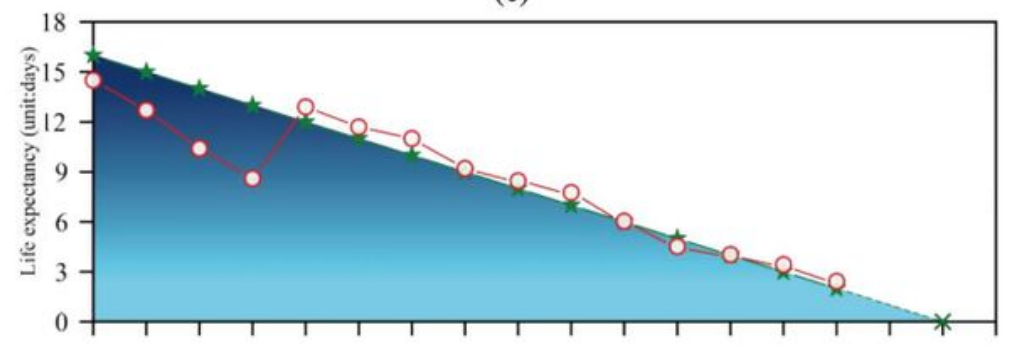

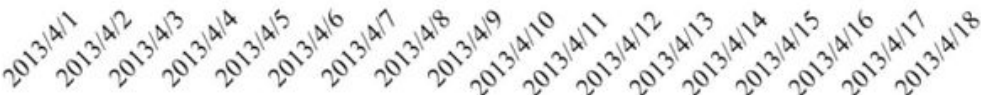

(d)

Figure 14

Life expectancy of Monitoring point 461 in elevation 3250 


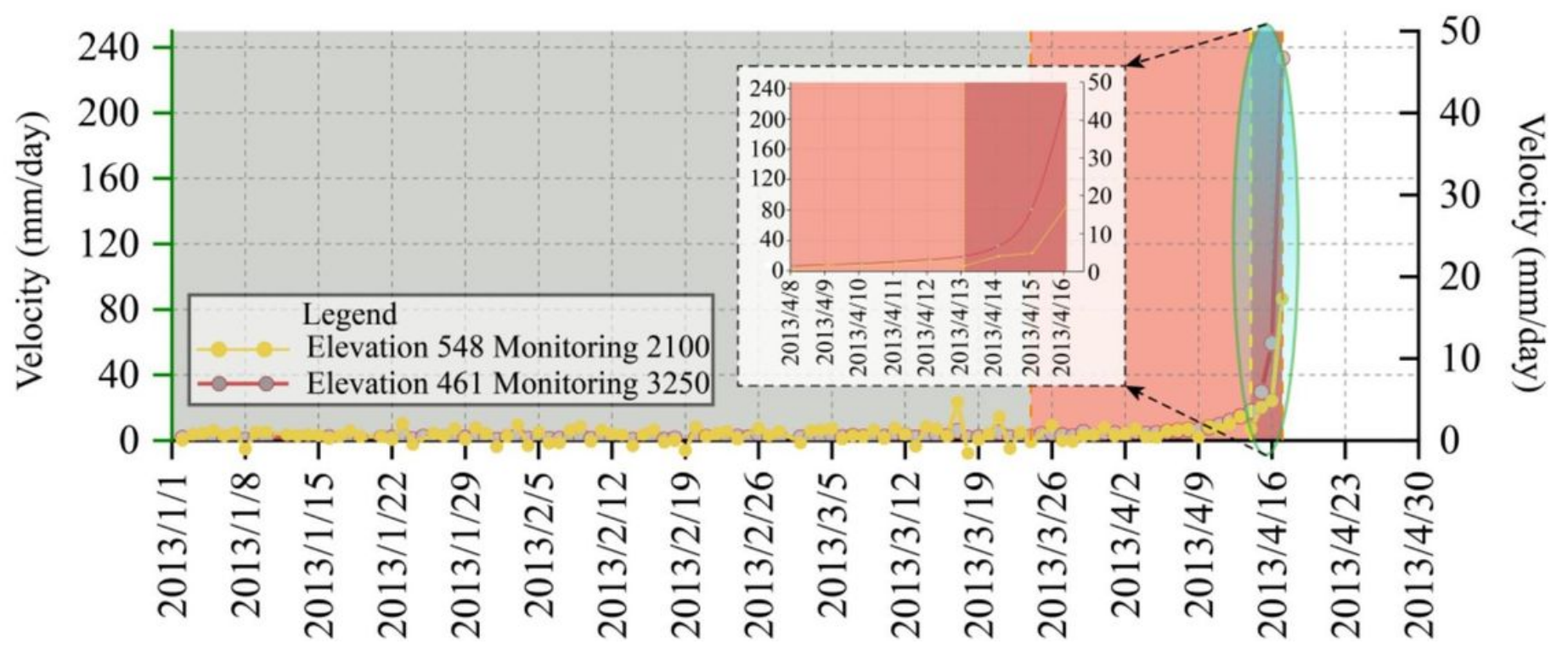

Figure 15

Diagram of displacement rate comparison of monitoring points 548-2100 and 461-3250 

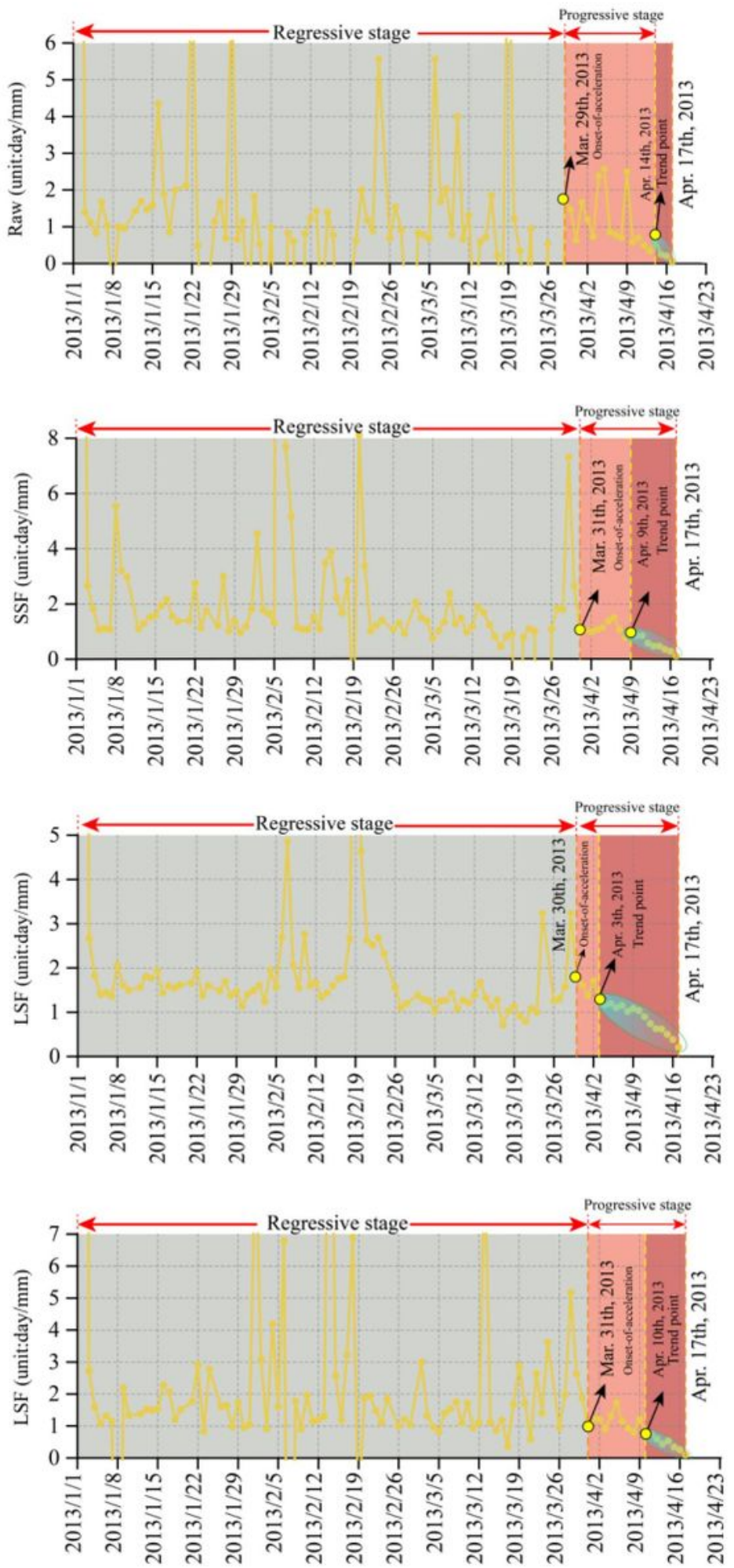

\section{Figure 16}

Schematic diagram of landslide time prediction based on reciprocal velocity data of 548-2100 time series model at monitoring points (a) Raw Data; (b) SSF; (c) LSF; (d) ESF. 


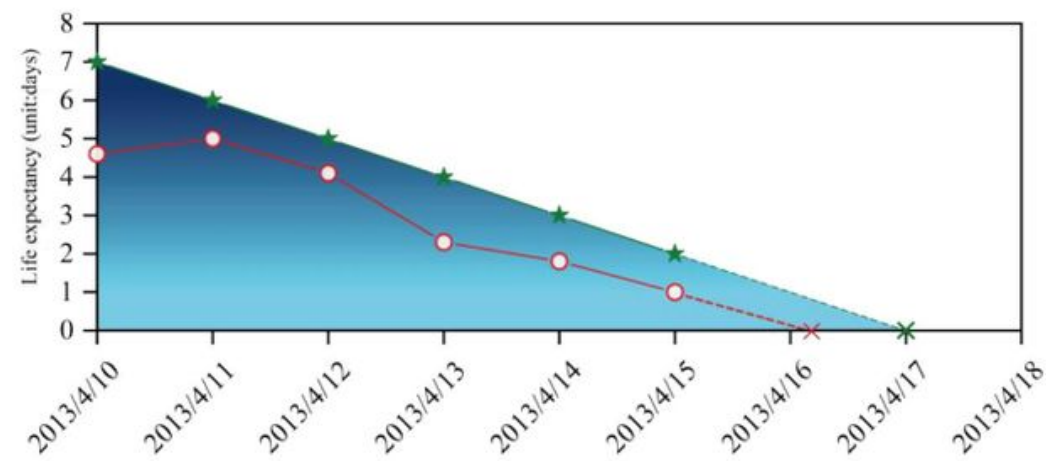

(a)

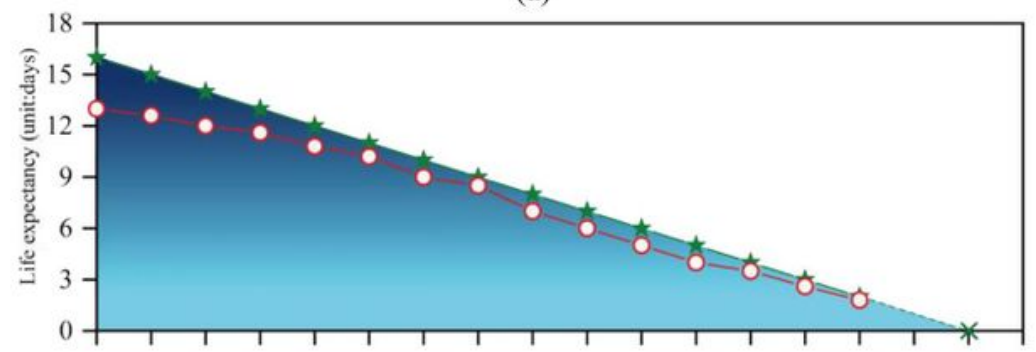

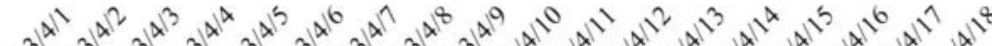

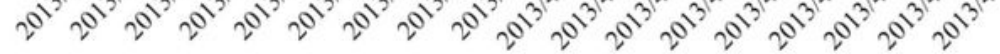
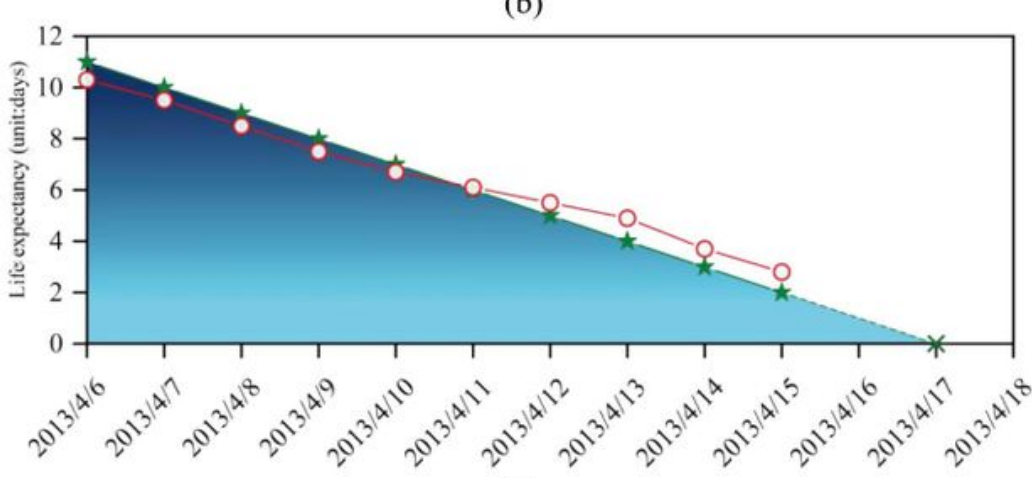

(c)

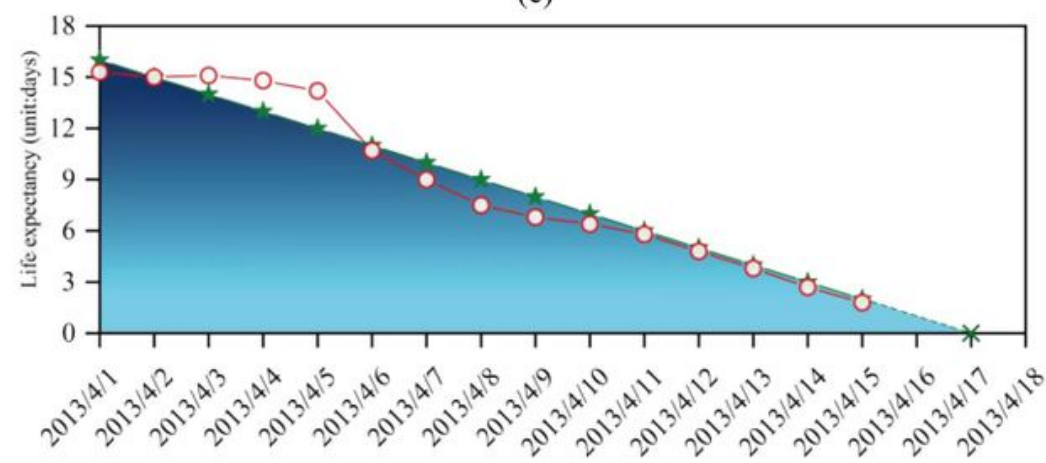

(d)

Figure 17

Life expectancy of Monitoring point 548 in elevation 2100 


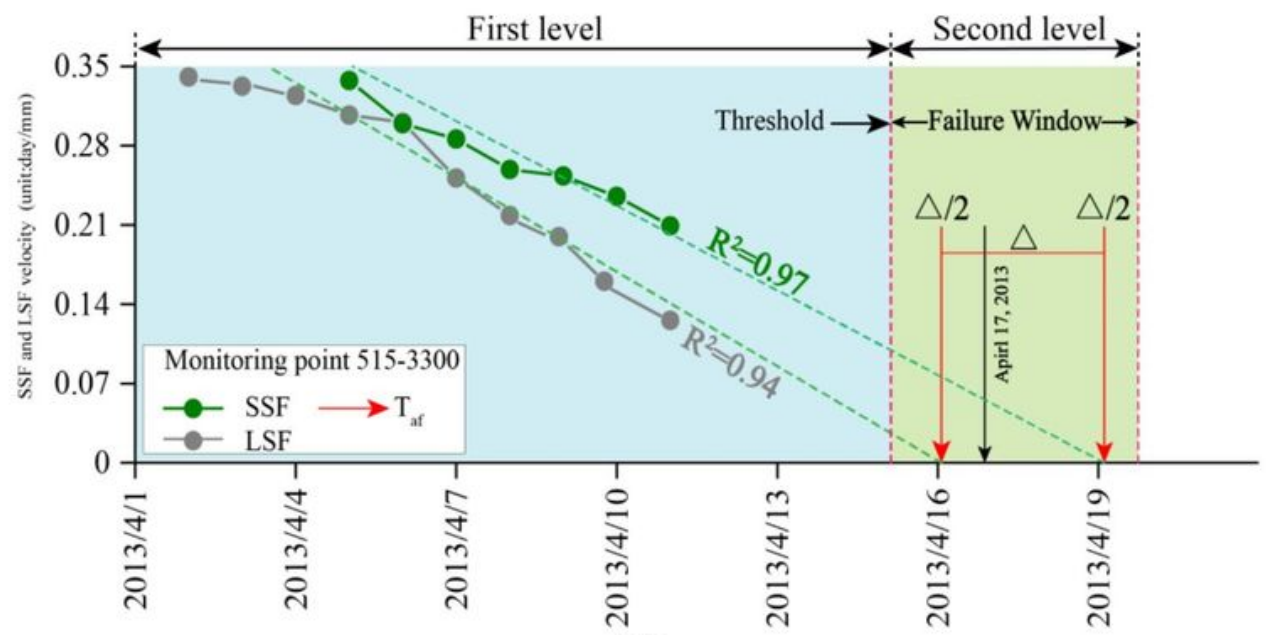

(a)

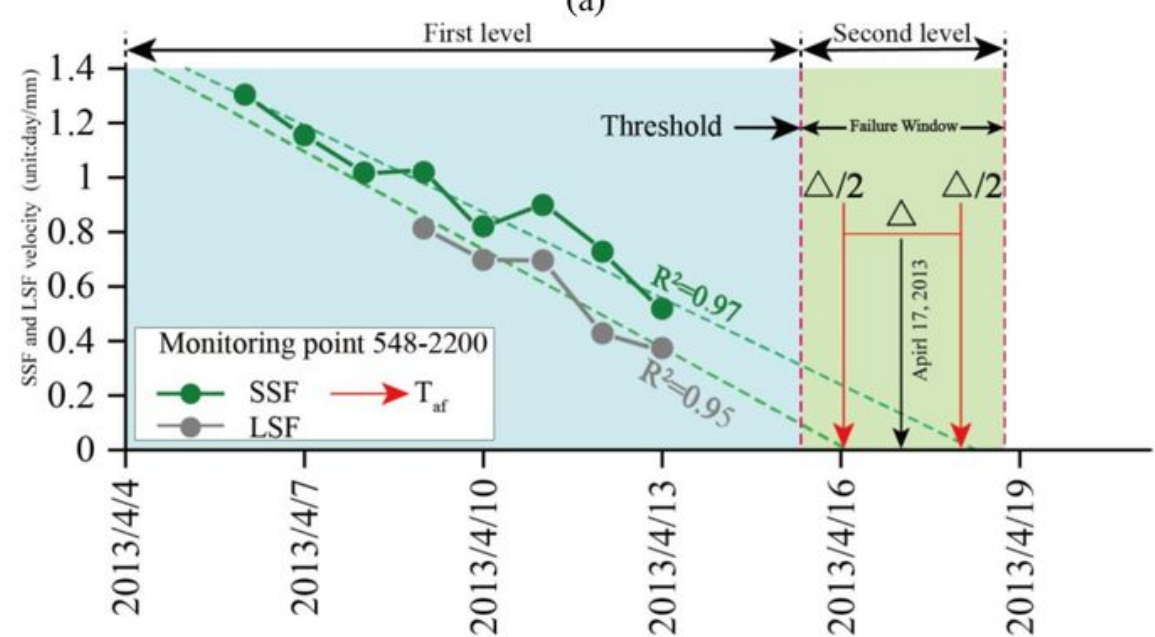

(b)

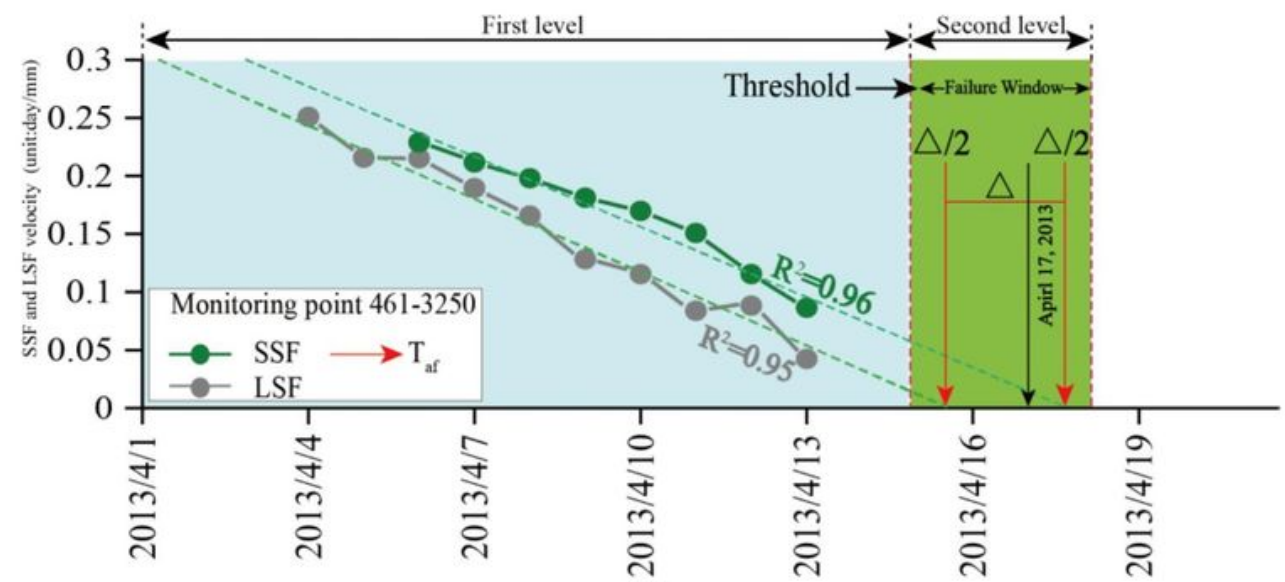

(c)

\section{Figure 18}

The time window expression of slope failure feedback from monitoring points 515-3300, 548-2200 and 461-3250 